\title{
Demonstration of space-resolved $x$-ray Thomson scattering capability for warm dense matter experiments on the $Z$ accelerator
}

\author{
T. Ao, E. C. Harding, J. E. Bailey, \\ R. W. Lemke, M. P. Desjarlais, S. B. Hansen, I. C. Smith, M. Geissel, \\ A. Maurer, J. Reneker, D. Romero, D. B. Sinars, G. A. Rochau, and J. F. Benage
}

Sandia National Laboratories, Albuquerque, NM, USA

\begin{abstract}
Experiments on the Sandia $\mathrm{Z}$ pulsed-power accelerator have demonstrated the ability to produce warm dense matter (WDM) states with unprecedented uniformity, duration, and size, which are ideal for investigations of fundamental WDM properties. For the first time, space-resolved x-ray Thomson scattering (XRTS) spectra from shocked carbon foams were recorded on $\mathrm{Z}$. The large (>20 MA) electrical current produced by $\mathrm{Z}$ was used to launch Al flyer plates up to $25 \mathrm{~km} / \mathrm{s}$. The impact of the flyer plate on a $\mathrm{CH}_{2}$ foam target produced a shocked state with an estimated pressure of $0.75 \mathrm{Mbar}$, density of $0.52 \mathrm{~g} / \mathrm{cm}^{3}$, and temperature of $4.3 \mathrm{eV}$. Both unshocked and shocked portions of the foam target were probed with $6.2 \mathrm{keV}$ x-rays produced by focusing the Z-Beamlet laser onto a nearby Mn foil. The data is composed of three spatially distinct spectra that were simultaneously captured with a single spectrometer with high spectral $(4.8 \mathrm{eV})$ and spatial $(190 \mu \mathrm{m})$ resolutions. Detailed spectral information from three target locations is provided simultaneously: the incident x-ray source, the scattered signal from unshocked foam, and the scattered signal from shocked foam.
\end{abstract}




\section{Introduction}

Measuring the physical properties (e.g. temperature, density, phase, structure factor, and ionization state) of dense plasma and warm dense matter (WDM) is experimentally challenging. With temperatures about 1-100 eV and electron densities of order $10^{20}-10^{24} \mathrm{~cm}^{-3}$, these high energy density (HED) states [1] are comparable to conditions within brown dwarf stars and Jovian planets [2, 3], and of interest to inertial confinement fusion (ICF) research $[4,5]$. The properties of WDM are difficult to diagnose because the temperatures are too low to excite spectral emission lines and the high densities preclude optical probes from interrogating the interior conditions. This has provided the impetus to develop multi-keV x-ray diagnostics able to penetrate into the dense plasma matter states [6].

The motivation for this work arises from the conjunction of two progress streams of experimental capabilities in HED physics. First, experiments on the Sandia Z pulsedpower accelerator [7] have demonstrated the ability to produce WDM samples with unprecedented uniformity, duration, and size. However, direct measurements to date have been limited mainly to density and pressure. Temperature measurements have been performed only on transparent samples that are compatible with optical emission diagnostics. Thus, the temperature information that is essential for the completion of the equation of state is missing for many materials. Of even greater interest is the fundamental behavior of atoms embedded in HED plasmas that control the temperature, pressure, and density conditions. However, this behavior poses challenges for theory to accurately describe, and it is difficult to experimentally address with the measurement of bulk material properties. 
The second progress stream is the development of x-ray probe sources from highpower lasers $[8,9]$ and $4^{\text {th }}$ generation synchrotrons [10]. A variety of experiments have demonstrated remarkable promise for diagnosing internal HED sample conditions using $\mathrm{x}$-ray radiography $[11,12,13]$, x-ray diffraction $[14,15]$, x-ray absorption spectroscopy $[16,17,18,19]$, and x-ray Thomson scattering (XRTS) $[20,21]$ methods. The term "xray Thomson scattering" is used in the literature to refer to the combination of processes that contribute to spectrally-resolved scattered photon observations. These processes include Compton (inelastic) and Rayleigh (elastic) scattering in the non-collective regime and plasmon and Rayleigh scattering features in the collective regime. A variety of analysis methods exist and which method is appropriate depends on the plasma conditions. A unifying theme is that the density, temperature, and ionization information can be extracted from spectral energy shifts, the spectral shape, and the relative intensities of the different scattered features.

Glenzer, et al. [22, 23] performed pioneering XRTS measurements on isochorically laser-heated solid beryllium targets, which demonstrated the ability of XRTS to extract previously elusive WDM properties. Later, the $\mathrm{x}$-ray scattering technique has been used to probe laser shock-compressed matter, such as plastic $(\mathrm{CH})$ and $\mathrm{Br}$-doped $\mathrm{CH}$ foils [24], aluminum [25, 26], lithium [27], lithium-hydride [28], beryllium [29, 30], and boron [31]. However, these prior laser-driven experiments had the following limitations: (1) the measured x-ray scattering signal was spatially integrated, (2) the x-ray source was not measured during the x-ray scattering shot, and (3) for the shocked systems, spatial and temporal variations existed. Because all of these laserdriven experiments have inherently small scattering volumes $\left(\sim 0.01 \mathrm{~mm}^{3}\right)$ and short 
steady-state durations ( $1 \mathrm{~ns}$ ), highly oriented pyrolytic graphite (HOPG) crystal spectrometers were used to obtain measurable $\mathrm{x}$-ray scattering signal. In contrast to ideal crystals, HOPG is a mosaic crystal consisting of many small crystallites that enable high integral reflectivity [32]. However, these bulk mosaic HOPG crystal spectrometers only have spectral resolutions of $E / \Delta E \sim 300[33,34]$, which are insufficient to resolve subtle features of the scattered x-rays. Even more important, the spatial resolution of HOPG crystal spectrometers is severely limited due the spread in crystallite orientations, thus identifying the space dependent scattering contributions is challenging. Recently, Gamboa et al. $[35,36]$ performed space-resolved XRTS measurements, using a doublefocusing toroidally-bent germanium crystal, of laser-driven blast waves within lowdensity carbon foams. The blast wave was made evident from the 1D imaging of the elastic scattering, which showed an increase in the signal intensity across the shock front. However, fitting the spatial intensity profile to a theoretical model revealed preheating of the foam upstream of the shock, and simultaneous measurement of the x-ray source during the shock loading was not obtained.

This paper describes experiments that were performed to implement the complex XRTS technique on the Sandia Z pulsed-power accelerator. The overall goal of the work was to demonstrate the ability to measure a space-resolved $\mathrm{x}$-ray scattering signal from a well-defined, uniform WDM sample. A magnetically launched flyer plate drove a strong shock into a $\mathrm{CH}_{2}$ foam sample, which was probed with $6.2 \mathrm{keV}$ x-rays from a manganese (Mn) plasma generated by the Z-Beamlet laser (ZBL). The uniformly shocked $\mathrm{CH}_{2}$ volume is about $10 \mathrm{~mm}^{3}$, and the steady shock state lasts about $100 \mathrm{~ns}$, values that are on order of 1000 and 100 times larger, respectively, than typical laser shocked samples. We 
successfully recorded space-resolved scattered x-ray spectra from the foam regions ahead and behind the shock, and simultaneously measured the source x-ray spectrum. To the best of our knowledge, this is the first experiment anywhere to successfully record this combination of signals. This, coupled with the uniform and steady shock conditions produced, will enable novel x-ray scattering investigations of WDM on the $\mathrm{Z}$ machine. Finally, the results from multiple experiments demonstrated the impressive reproducibility of the shock states generated on $\mathrm{Z}$. 


\section{Experimental description}

The overall Z-XRTS experimental setup is shown in Figure 1. The three key components of the Z-XRTS experiments are the Z-Dynamic Materials Properties (DMP) load, the Z-Beamlet laser (ZBL), and the x-ray scattering spherical spectrometer (XRS3). As shown in Figure 2, ZBL irradiates a metal x-ray source foil place near the back surface of a sample. The x-rays penetrate the shocked sample and scatter out the side of the sample. The XRS3 diagnostic is setup perpendicular to the shock propagation direction to collect X-rays scattered from both shocked and ambient states of the sample, as well as the incident x-rays. This allows in situ comparison of the WDM state with the unperturbed material state, and the x-ray probe spectrum to be characterized simultaneously.

\subsection{Z-DMP load}

The magnetic loading technique using pulsed-power generators for DMP studies is described in Ref. [37], so only a brief overview is presented here. $\mathrm{Z}$ is a large pulsedpower facility ( $30 \mathrm{~m}$ in diameter), which can produce a shaped electrical pulse with highly controllable risetime (100-1000 ns) and peak current of about $26 \mathrm{MA}$. The ZDMP coaxial load consists of two anode (north and south) plates arranged around a central cathode stalk to form two anode-cathode (A-K) vacuum gaps, as shown in Figure 3. The short circuit is created between the anode plates and the cathode stalk through a shorting cap at the top of the coaxial load. The current density $\mathrm{J}$ flowing on the anode and cathode produces a planar magnetic field $\mathrm{B}$ between them, and the $\mathrm{J} \times \mathrm{B}$ force produces a smooth mechanical stress wave that is proportional to the magnetic field 
squared (see Figure 2 (a)). The generated impulsive pressure provides sufficient momentum to launch the aluminum ( $\mathrm{Al})$ anode flyer plates at high velocities across the gap toward samples located on the load assemblies [38]. The flyer plates impact the samples at openings along the load assemblies. Since the Z-DMP load is macroscopic in size ( $35 \mathrm{~mm}$ wide, $56 \mathrm{~mm}$ high, $20 \mathrm{~mm}$ thick), it enables numerous (4-7) samples to be placed vertically along each of the north and south assemblies that experience nearly identical impact conditions. On the Z-XRTS experiments, XRTS data was measured from large polyethylene $\left(\mathrm{CH}_{2}\right)$ foam samples $\left(0.12 \mathrm{~g} / \mathrm{cm}^{3}\right.$ in density, $5.0 \mathrm{~mm}$ wide, 7.5 $\mathrm{mm}$ high, $2.5 \mathrm{~mm}$ thick) located on the top north location (see Figure 3). The height of the $\mathrm{CH}_{2}$ foam was extended up the load assembly to delay possible edge ejecta until well after ZBL irradiates the $\mathrm{Mn} \mathrm{x}$-ray target. The $\mathrm{CH}_{2}$ foam samples were chosen for the commissioning of the XRTS capability on $\mathrm{Z}$ because their ambient density could be precisely tailored to allowed deep penetration of $6.2 \mathrm{keV}$ x-rays (attenuation length of about $10 \mathrm{~mm}$ ) into them. Thus, a thick sample could be used to produce a very long shocked steady-state duration that would be insensitive to any possible timing jitters between ZBL and Z. The SESAME 7171 equation-of-state (EOS) for polyethylene was used to predict the $\mathrm{CH}_{2}$ foam shock state.

Figure 4 shows the density and temperature profiles predicted by the magnetohydrodynamic (MHD) code ALEGRA [39] of the shocked $\mathrm{CH}_{2}$ state $(0.75$ Mbar) from the impact of a solid Al flyer with a peak velocity of $25 \mathrm{~km} / \mathrm{s}$. As the current flows on the anode plate interior, Joule heating steadily burns away the initial Al flyer thickness of $1.20 \mathrm{~mm}$. Nonetheless, at impact about $0.30 \mathrm{~mm}$ of solid Al still remains to launch a strong shock into the $\mathrm{CH}_{2}$ foam. The shock wave propagates in $\mathrm{CH}_{2}$ at a 
velocity of $29.0 \mathrm{~km} / \mathrm{s}$, and is followed by a release wave moving at $68.0 \mathrm{~km} / \mathrm{s}$ that eventually catches up to the shock. At $40 \mathrm{~ns}$ after impact, the shock front has traveled $1.15 \mathrm{~mm}$ into the $\mathrm{CH}_{2}$, and produces a $0.25 \mathrm{~mm}$ thick WDM state with shock density $\left(0.52 \mathrm{~g} / \mathrm{cm}^{3}\right.$ or more than four times its initial density) and temperature $(4.3 \mathrm{eV})$ that are undisturbed by the release wave. Along the shock propagation direction, a slight spatial gradient is formed as the release wave attenuates the WDM state, which overtakes the shock front at $80 \mathrm{~ns}$ after impact. However, the trailing Al flyer material acts as a tamper and prevents complete unloading of the WDM state, thus there is only $3-4 \%$ variation in the density and temperature profiles at that time.

\subsection{ZBL x-ray source}

The ZBL beam [40] was transported to the top of the $\mathrm{Z}$ center section chamber, passes through the final optics assembly (FOA) consisting of a turning mirror and a $3.2 \mathrm{~m}$ focal length lens, and entered the Z-DMP load region through a hole in the blast shield top lid. Inside the blast shield, the ZBL beam passed through three baffle plates and an aperture block above the Z-DMP load, before being focused onto the metal x-ray source target (see Figure 1.) The x-ray source targets were fabricated from 5-10 $\mu \mathrm{m}$ thick manganese (Mn) foils backed by a $0.10 \mathrm{~mm}$ thick layer of polyester. ZBL was optimized to provide $2-4 \mathrm{~kJ}$ of laser energy $(\lambda=527 \mathrm{~nm}, 0.5 \mathrm{~ns}$ pre-pulse, $2-3.5 \mathrm{~ns}$ main-pulse, focused to $\left.\sim 2 \times 10^{15} \mathrm{~W} / \mathrm{cm}^{2}\right)$ to generate the bright Mn-He- $\alpha(6181 \mathrm{eV})$ emission for XRTS. X-ray source characterizations by Workman et al. [41] have shown the duration

of ns-laser generated $\mathrm{x}$-rays to be comparable to the laser pulse duration. Using results of ALEGRA calculations as a guide, the firing of ZBL was timed (about $70 \mathrm{~ns}$ after impact) 
to generate $\mathrm{x}$-rays after the shock front had propagated $2 \mathrm{~mm}$ into the $\mathrm{CH}_{2}$ foam, thus probing about a $0.5 \mathrm{~mm}$ thick shocked state and a remaining $0.5 \mathrm{~mm}$ thick ambient state.

\subsection{X-ray scattering spectrometer (XRS3)}

The XRS3 is a focusing spectrometer with spatial resolution [42], in which collected x-rays are spectrally and spatially resolved by a spherically-bent crystal, and recorded onto a Fuji-TR image plate (IP) $[43,44]$ or Agfa D8 x-ray film $[45,46]$. It uses a doubly-focusing geometry that enables overall high sensitivity and provides highresolution, space-resolved spectra. A detailed analysis of the image fluence and crystal throughput in this geometry was carried out and analytical estimates of these quantities are presented in Ref. [47]. The relative x-ray collection efficiency, spatial resolution, and spectral resolution of spherically-bent quartz, mica, germanium, and pyrolytic graphite crystals were investigated using a Manson x-ray source [48]. A spherically-bent germanium (Ge) 422 crystal (216 mm radius of curvature) was fielded in the Z-XRTS experiment because it had the best combination of spatial and spectral resolution, and $\mathrm{x}-$ ray collection efficiency. The Ge 422 crystal and the IP/film detector were housed inside a 1-inch thick tungsten box for debris and x-ray background shielding (see Figure 1). An entrance snout consisting of chevron (V-shaped) plates was meant to deflect load debris from entering the XRS3 box. In addition, several 1-inch thick tungsten internal crossover plates that only allow x-rays that are reflected off the crystal to reach the $\mathrm{IP} /$ film were used to further reduce x-ray background. The Ge 422 crystal was positioned $370 \mathrm{~mm}$ from the top north $\mathrm{CH}_{2}$ foam sample on the Z-DMP load, and set at a Bragg angle of $60.3^{\circ}$ relative to the x-rays entering the XRS3 box. Figure 5 presents detailed photographs of the Z-DMP load hardware, and the line-of-sight of the XRS3 diagnostic. 
The XRS3's field-of-view shows the $\mathrm{CH}_{2}$ foam sample, the tantalum (Ta) aperture, and the copper $(\mathrm{Cu})$ filter (see Figure 5 (b)). The x-rays scattered from the $\mathrm{CH}_{2}$ foam and viewed by XRS3 are limited to those passing through a $2 \mathrm{~mm}$ tall aperture of a $50 \mu \mathrm{m}$ thick Ta foil situated in front of the sample. Direct measurement of the bright Mn x-ray source would have completely saturated the XRS3's IP without any filtering. Thus, the source x-rays viewed by XRS3 were attenuated by a factor of about 1100 by the $75 \mu \mathrm{m}$ thick $\mathrm{Cu}$ foil in front of the Mn x-ray target in order to be about the same order of magnitude of the scattered x-rays, which enabled both to be simultaneously measured on the same detector.

\subsection{VISAR and XPC diagnostics}

In dynamic compression experiments, the density and pressure of the shocked state are determined from particle and shock velocities, which are measured using VISAR (velocimetry system for any reflector) [49,50]. Fielding a velocimetry probe on the $\mathrm{CH}_{2}$ foam sample in conjunction with the XRTS components might have caused additional complications between the diagnostics. It was considered more prudent to obtain the shocked $\mathrm{CH}_{2}$ state information by placing additional $\mathrm{CH}_{2}$ foam samples, backed by plastic (TPX) windows, on other available sample locations of the north and south assemblies. Transparent windows (e.g. sapphire, lithium fluoride, quartz, TPX, etc.) were placed at the remaining sample locations to directly measure the impact velocity of the flyer plates. An x-ray pinhole camera (XPC) diagnostic was mounted directly opposite XRS3, and used to monitor the x-rays generated from the ZBL irradiated Mn target (see Figure 6 (a)). The XPC was fielded with a $0.1 \mathrm{~mm}$ diameter 
tantalum pinhole, and a $0.5 \mathrm{~mm}$ thick Cirlex (Kapton) polyimide filter was used to reject low energy x-rays $(<4 \mathrm{keV})$.

\subsection{Challenges}

There were several experimental challenges for XRTS on Z, such as (1) x-ray background overwhelming the XRTS signal, (2) damage from load debris, (3) and interactions between $\mathrm{Z}$ and $\mathrm{ZBL}$. First, $\mathrm{Z}$ itself is a tremendous $\mathrm{x}$-ray source, where photons with energies up to $10 \mathrm{MeV}$ are produced in both the power feed sections and load region, thus sufficient signal-to-noise for the XRTS measurement needed to be validated. The XRS3 hardware with its thick layers of tungsten shielding was designed to suppress the x-ray background, and was tested as a ride along diagnostic on several prior Z-DMP experiments. It was shown that Z-DMP experiments have significantly lower $\mathrm{x}$-ray background than the extreme radiation producing z-pinch experiments performed on $\mathrm{Z}[51,52]$. The $\mathrm{x}$-ray background at the bottom entrance of the XRS3 tungsten box where the spherically-bent crystal sits was on order of several PSL (photostimulated luminescence). This was further reduced by a factor of 30 using internal tungsten crossover plates, so that only about $0.01-0.3$ PSL of x-ray background was measured at the IP. This modest X-ray background makes XRTS viable on Z-DMP experiments, where typical scattering signals levels are of order 0.1 PSL.

Second, $\mathrm{Z}$ is a very destructive environment, where about 2-3 MJ (an energy release comparable to a stick of dynamite) is deposited into the load hardware, which explodes via magnetic pressure sending debris in all directions. The primary concern is vertically directed debris damaging the ZBL FOA and creating a catastrophic vacuum 
breach of the target chamber. A sacrificial $10 \mathrm{~mm}$ thick glass debris shield is placed below the ZBL FOA window (30 mm thick glass) to stop any debris from reaching it. In addition, an aperture block near the load and baffle plates within the blast shield above it served to limit the axial debris (see Fig 1). Another concern is debris entering the XRS3 spectrometer and damaging the IP, thereby preventing retrieval of the XRTS data. The entrance snout deflected most debris from entering the XRS3, thus IP was undamaged and XRTS data was recovered. However, the spherical crystal was still damaged by the remaining undeflected projectiles.

Finally, although monochromatic backlighting of z-pinch experiments with ZBL generated x-rays [13] are routinely performed on Z, coupling of ZBL with Z-DMP experiments presented some additional interactions between the two platforms. First, synchronizing the firing time of ZBL to generate $\mathrm{x}$-rays to probe the sample's shocked WDM state depends upon precise knowledge of the flyer velocity and impact time. With proper load design and tailoring of the current pulse shape, an Al flyer plate can be magnetically accelerated quasi-isentropically to ultrahigh velocity that agree well with MHD simulations [38]. Nonetheless, anomalous current loss away from the Z-DMP load during a $\mathrm{Z}$ experiment does infrequently occur, which causes the measured flyer velocity to be lower than the predicted flyer velocity. In those instances, the ZBL generated xrays arrive too early relative to the shock formation within the sample. Second, the ZDMP coaxial load was chosen instead of a stripline load [53] because the latter design consisted only of two parallel (anode and cathode) plates where current flow and magnetic fields are not constrained within the A-K gap, and so any generated plasma could interfere with the ZBL beam. In the coaxial design, the region formed by the anode 
plates and shorting cap that surround the cathode stalk was expected to fully confine the current flow and magnetic fields. However, it was discovered that at the shorting cap a small amount of current leaks out to form plasma, which disrupted the ZBL path to the $\mathrm{Mn}$ target and resulted in very weak x-ray production in preliminary experiments. These experimental challenges were thoroughly addressed and mitigation schemes were implemented. As a result the Z-XRTS capability was successfully commissioned, and the first XRTS of shocked WDM samples have been measured on Z. 


\section{Results}

In this section, the results of three Z-XRTS experiments (Z2661, Z2704, and $\mathrm{Z} 2750$ ) are presented. The $\mathrm{Al}$ flyer, $\mathrm{CH}_{2}$ foam sample, and $\mathrm{ZBL}$ parameters for those $\mathrm{Z}$ XRTS experiments are listed in Tables 1,2 and 3, respectively. Table 4 lists the measured x-ray background, source, and scattering values corresponding to each experiment.

\subsection{Backward scattering}

To maximize the $\mathrm{x}$-ray fluence, no aperture between the $\mathrm{x}$-ray source and sample was used to limit the amount of x-rays incident on the sample on experiments Z2661 and Z2704. Consequently, the measured $\mathrm{x}$-ray scattering consisted of distribution of angles, as shown Figure 7 (a). Based on the distance of the Mn x-ray source from the sample rear surface $(0.75 \mathrm{~mm})$ and the sample width $(5.0 \mathrm{~mm})$, it was possible for scattering angles between $17^{\circ}-163^{\circ}$ and $42^{\circ}-138^{\circ}$, to have occurred at the $\mathrm{CH}_{2}$ foam's rear and front surfaces, respectively. However, the majority of the scattered x-rays that were recorded by the XRS3 diagnostic most likely originated from the middle of the sample around the $90^{\circ}$ scattering angle due to $\mathrm{x}$-ray source and geometric considerations. First, previous characterization of the $\mathrm{Mn} \mathrm{He}-\alpha$ x-ray source has shown that the $\mathrm{x}$-ray intensities at shallow angles were about half of that at near normal angle. Second, the shallow angle scattering $\mathrm{x}$-ray fluence is reduced due to the longer distance $\mathrm{x}$-rays have to propagate to reach the sample's edge compared to the distance to sample's middle for near normal angle x-ray scattering. 


\subsubsection{Image plate measurement}

On Z2661, we successfully recorded the $1^{\text {st }}$ space-resolved scattered x-ray spectra from $\mathrm{CH}_{2}$ foam regions ahead and behind the shock, and simultaneously measured the source x-ray spectrum. Figure 8 (a) displays the VISAR measured Al flyer velocity profile for Z2661, which closely matched the ALEGRA expected Al flyer velocity profile. Specifically, the measured impact velocity $\left(U_{\text {VISAR-impact }}=25.47 \mathrm{~km} / \mathrm{s}\right)$ and measured impact time ( $\left.t_{V I S A R-\text { impact }}=3264.3 \mathrm{~ns}\right)$ agreed very well with the expected impact velocity $\left(U_{\text {ALEGRA-impact }}=25.24 \mathrm{~km} / \mathrm{s}\right)$ and expected impact time $\left(t_{\text {ALEGRA-impact }}=3365 \mathrm{~ns}\right)$. Thus, the measured $\mathrm{CH}_{2}$ shock state should be close to the predicted $\mathrm{CH}_{2}$ shock state (0.75 Mbar in pressure, $0.52 \mathrm{~g} / \mathrm{cm}^{3}$ in density, $4.3 \mathrm{eV}$ in temperature) shown in Figure 4.

The VISAR measured shock breakout time at $t_{\text {VISAR-breakout }}=3350.4 \mathrm{~ns}$ corresponded to a $86.1 \mathrm{~ns}$ shock transit time, thus the $29.05 \mathrm{~km} / \mathrm{s}$ measured shock velocity agreed very well with the $29.0 \mathrm{~km} / \mathrm{s}$ expected shock velocity. The ZBL beam consisted of a $400 \mathrm{~J}$ pre-pulse ( $0.4 \mathrm{~ns})$ and a $2580 \mathrm{~J}$ main-pulse ( $2.0 \mathrm{~ns})$ with a $3.3 \mathrm{~ns}$ prepulse lead time, which was fired into the $\mathrm{Z}$ center section at $t_{Z B L}=3335.0 \mathrm{~ns}$ and focused onto a $5 \mu \mathrm{m}$ thick Mn foil. A motion blur of about $60 \mu \mathrm{m}$ was estimated from the $\mathrm{CH}_{2}$ shock velocity and the x-ray pulse duration. Figure 6 (b) displays the pinhole image of the $6.2 \mathrm{keV}$ Mn x-ray source recorded by the XPC diagnostic, which indicated that the ZBL beam path was unobstructed. Parallel to the Mn foil surface, the x-ray spot was relatively symmetric and had a full-width-half-maximum (FWHM) of $450 \mu \mathrm{m}$. Perpendicular to the Mn foil surface, the x-ray spot had a FWHM of $185 \mu \mathrm{m}$, but displayed skewness due to the laser-heated plasma expanding away from the surface. 
Figure 9 (a) displays the raw x-ray data recorded by the XRS3 diagnostic on the IP, which was scanned on a Fuji BAS-5000 scanner with the following settings: Sensitivity S1000, Latitude L4, and Scan Resolution $25 \mu \mathrm{m}$. The response of the IP was shown to be linear over a dynamic range of 5 orders of magnitude by Gates et al. [43]. The multiple satellite lines of the Mn He- $\alpha$ emission were spectrally well resolved, and three spatially distinct $\mathrm{x}$-ray spectra were simultaneously recorded: the source, the ambient $\mathrm{CH}_{2}$ foam, and the shocked $\mathrm{CH}_{2}$ foam. Specifically, the $\mathrm{x}$-ray scattering as a function of depth into the $\mathrm{CH}_{2}$ foam displayed higher signal (0.845 PSL) from the shocked state compared to the signal (0.550 PSL) from the ambient state. This was in mark contrast to the x-ray scattering signal from $\mathrm{CH}_{2}$ foam, which decays exponentially with sample depth [54]. For Z2661, the measured x-ray background baseline and noise were 0.334 PSL and 0.045 PSL, respectively. Further analysis of the XRTS data involving x-ray background removal, and spectral and spatial filtering is presented in Section 4 .

\subsubsection{Film measurement}

Although IP has the advantages of high sensitivity and large dynamic range, it displays only a moderate spatial resolution. The XRS3 IPs were scanned with a scan step of $25 \mu \mathrm{m}$, but IP characterizations have shown the effective spatial resolution of IP to be about 63-94 $\mu \mathrm{m}[48,55]$. The submicron grain sizes of x-ray films such as Agfa D4, D7, D8 and Kodak SR45 [45] enable them to have better spatial resolution than IP, but they also have considerably lower sensitivity than IP to $6.2 \mathrm{keV}$ x-rays. On the other hand, $\mathrm{x}$ ray background on the film may be lower since IP is more sensitive to high-energy 
photons present in the $Z$ environment, and film's higher spatial resolution could help mitigate lower sensitivity due to the lines being sharper. The impact of higher spatial resolution, lower sensitivity to the desired signal, and lower sensitivity to the high-energy $\mathrm{x}$-ray background is difficult to assess without actually performing the experiment on $\mathrm{Z}$. Thus, the goal of the next Z-XRTS experiment (Z2704) was to determine the feasibility of recording x-ray scattering data on x-ray film.

For Z2704, the same Z shot parameters as Z2661 were used to launch an Al flyer to impact a $\mathrm{CH}_{2}$ foam sample. Figure 8 (b) displays the VISAR measured Al flyer velocity profile for Z2704 $\left(U_{V I S A R-\text { impact }}=25.41 \mathrm{~km} / \mathrm{s}\right.$, and $\left.t_{V I S A R-\text { impact }}=3265.2 \mathrm{~ns}\right)$, which once again closely matched the ALEGRA prediction. The VISAR measured shock breakout time at $t_{V I S A R-\text { breakout }}=3352.5 \mathrm{~ns}$ corresponded to an $87.3 \mathrm{~ns}$ shock transit time, and the $28.55 \mathrm{~km} / \mathrm{s}$ measured shock velocity.

The ZBL beam consisted of a $230 \mathrm{~J}$ pre-pulse $(0.4 \mathrm{~ns})$ and a $3250 \mathrm{~J}$ main-pulse (3.5 ns) with a $1.8 \mathrm{~ns}$ pre-pulse lead time, which was fired into the $\mathrm{Z}$ center section at $t_{Z B L}$ $=3333.6 \mathrm{~ns}$ and focused onto a $5 \mu \mathrm{m}$ thick Mn foil. More energy was added to the ZBL main-pulse to increase $\mathrm{x}$-ray output, but this required lengthening its pulse duration in order to prevent damage to the laser optics. The longer x-ray pulse duration corresponded to a still-acceptable motion blur of about $100 \mu \mathrm{m}$. Figure 9 (b) displays the raw X-ray data recorded by the XRS3 diagnostic for Z2704. Inside the XRS3 diagnostic, Agfa D8 x-ray film was fielded in place of IP. The film survived the Z-XRTS experiment and showed no evidence of fogging. The developed film was digitized using a Perkin-Elmer microdensitometer with matched optics of 0.1 numerical aperture and a scan box of $13 \mu \mathrm{m}$ per side. Previous characterizations by Lanier et al. $[45,46]$ have 
shown that within the spectral and intensity range of the Z-XRTS experiments the measured optical density (OD) of the D8 film is linear with $\mathrm{x}$-ray exposure (photons $/ \mu \mathrm{m}^{2}$ ). For Z2704, the respective x-ray background baseline and noise values were 0.099 OD and $0.027 \mathrm{OD}$, while the respective peak $\mathrm{x}$-ray scattering signals from ambient and shocked $\mathrm{CH}_{2}$ were $0.215 \mathrm{OD}$ and $0.258 \mathrm{OD}$.

\subsection{Forward scattering}

For future Z-XRTS experiments, a forward scattering geometry will be used to provide valuable information of WDM state in the collective regime, but will require more stringent collimation of the x-ray source. The new forward scattering geometry was achieved by placing a gold foil ( $0.1 \mathrm{~mm}$ thick) with a $1.0 \mathrm{~mm}$ wide opening on the rear of the $\mathrm{CH}_{2}$ foam sample and moving the $\mathrm{Mn} \mathrm{x}$-ray source laterally $1.0 \mathrm{~mm}$ away from the rear opening, as shown in Figure 7 (b). This setup produced a center scattering angle of $30^{\circ}$, and limited the range of possible scattering angles between $22^{\circ}-38^{\circ}$.

For Z2750, the same shot parameters as Z2661 and Z2704 were used to launch an Al flyer to impact a $\mathrm{CH}_{2}$ foam sample. Figure 8 (c) displays the VISAR measured $\mathrm{Al}$ flyer velocity profile for Z2750. For this experiment, the measured impact velocity $\left(U_{V I S A R-i m p a c t}=25.62 \mathrm{~km} / \mathrm{s}\right)$ was slightly higher than the ALEGRA prediction and the velocities of Z2661 and Z2704. As a result, the measured impact time $\left(t_{\text {VISAR-impact }}=\right.$ $3262.1 \mathrm{~ns}$ ) on Z2750 was about $3 \mathrm{~ns}$ earlier than expected, but this was still well within the acceptable time frame to enable the XRTS measurement of the shocked $\mathrm{CH}_{2}$ state. The VISAR measured shock breakout time at $t_{\text {VISAR-breakout }}=3347.4 \mathrm{~ns}$ corresponded to 
an $85.3 \mathrm{~ns}$ shock transit time, thus the $29.41 \mathrm{~km} / \mathrm{s}$ measured shock velocity was comparable to the predicted value $29.0 \mathrm{~km} / \mathrm{s}$.

The ZBL beam consisted of a $150 \mathrm{~J}$ pre-pulse $(0.4 \mathrm{~ns})$ and a $3800 \mathrm{~J}$ main-pulse (3.5 ns) with a $1.9 \mathrm{~ns}$ pre-pulse lead time $\mathrm{ZBL}$, which was fired into the $\mathrm{Z}$ center section at $t_{Z B L}=3334.8 \mathrm{~ns}$ and focused onto a $10 \mu \mathrm{m}$ thick Mn foil. Additional x-ray source characterizations showed that along with more laser energy, the Mn foil needed to be thicker to enable more material for x-ray generation. Figure 9 (c) displays the raw x-ray data recorded by the XRS3 diagnostic for Z2750. Additional shielding was fielded on the XRS3 diagnostic, which reduced the IP x-ray background baseline to 0.099 PSL and noise to $0.022 \mathrm{PSL}$. Once again, the x-ray scattering as a function of depth into the $\mathrm{CH}_{2}$ foam displayed higher signal (0.257 PSL) from the shocked state compared to the signal (0.184 PSL) from the ambient state. The increased x-ray source output and finer control of x-rays for the forward scattering geometry will enable benchmark quality data for material models to be obtained on future Z-XRTS experiments. 


\section{Discussion}

In this section, the analysis of the XRS3 data from the Z-XRTS experiments is discussed. X-ray background removal and 2D image filtering were performed on the raw XRS3 data presented in Section 3. Lineouts taken along the position coordinate were used to identify the x-ray contributions from three spatially distinct regions: the Mn source, the ambient $\mathrm{CH}_{2}$ foam, and the shocked $\mathrm{CH}_{2}$ foam. Lineouts taken along the energy coordinate at these three regions enabled direct spectral comparisons between ambient and shocked $\mathrm{CH}_{2}$ states.

\subsection{X-ray background removal and 2D image filtering}

The XRTS signal lay on top of an x-ray background that has both low and high frequency components, as displayed in varying degrees for each of the raw XRS3 images presented in Section 3 (see Figure 9). The x-ray background's slowly varying baseline (low frequency) and rapidly varying noise (high frequency) were filtered out with the following 2D digital signal processing. First, a 2D fast Fourier transform (FFT) was applied to the raw XRS3 data, and multiplied by a low frequency cutoff filter. After applying the inverse FFT, a leveled XRS3 image was created that had the x-ray background baseline removed. Applying a similar FFT analysis with a high frequency cutoff filter to the leveled XRS3 image could be used to remove the remaining x-ray background noise. However, the chosen high frequency cutoff would be somewhat arbitrary since it would be subject to a trade-off between the reduction of the noise itself and the resultant loss of detail in the XRTS signal. A more quantitative filtering scheme 
would incorporate the spatial and spectral resolutions of both the XRS3 diagnostic and relevant physical features of the XRTS signals.

A 2D smoothing filter was generated with spatial and spectral dimensions based on the following criteria. A detailed analysis of the image fluence and crystal throughput of the XRS3 diagnostic is presented Ref. [47]. The XRS3 was designed to enable an optimal spatial resolution of $190 \mu \mathrm{m}$. For the Z-XRTS experiment (Z2704) that used Xray film, the small intrinsic spatial resolution $(13 \mu \mathrm{m})$ of film would enable close to optimal spatial resolution. However, for the Z-XRTS experiments (Z2661 and Z2750) that used IPs, the larger intrinsic spatial resolution $(0.1 \mathrm{~mm})$ of the IP limited the effective spatial resolution of the XRS3 to about $260 \mu \mathrm{m}$. Similarly, the XRS3's effective spectral resolutions for x-ray film and IP were determined to be $4.8 \mathrm{eV}$ and 6.3 $\mathrm{eV}$, respectively. Applying a simple mean or median filter with the above spatial and spectral dimensions to the leveled XRS3 image would certainly have reduced the X-ray background noise. Alternatively, a weighted smoothing kernel based on the most intense and well-resolved Mn x-ray source spectral line offered a more physically meaningful filter, so the Mn He- $\alpha$ resonant $(E=6181 \mathrm{eV})$ line was chosen. The resultant filtered XRS3 data for the Z-XRTS experiments using their corresponding weighted smoothing kernels are displayed in Figures 10-12.

\subsection{Spatial and spectral comparisons}

This section presents the spatial and spectral lineouts of the filtered XRS3 data for the Z-XRTS experiment. The resultant filtered XRS3 image of Z2661 (see Figure 10 (a)) presented space-resolved x-ray spectra of the source, and definite scattering from both 
ambient and shocked $\mathrm{CH}_{2}$ states. A lineout taken along the position coordinate at the $\mathrm{Mn}$ He- $\alpha$ resonance line $(E=6181 \mathrm{eV})$ is shown in Figure $10(\mathrm{~b})$. The accuracy of the foam sample's location was estimated to within about $100 \mu \mathrm{m}$ based on the load assembly tolerances and the pointing accuracy of ZBL. The space-resolved x-ray scattering signal has a peak deep inside the $\mathrm{CH}_{2}$ sample $(x=-0.60 \mathrm{~mm})$ and clearly revealed the existence of a shocked $\mathrm{CH}_{2}$ state, which directly contrasts the exponentially decaying scattering profile from only an ambient state [54]. At the back of the foam, the signal drops off at interface with the $\mathrm{Al}$ flyer, which strongly attenuates the $6.2 \mathrm{keV}$ x-rays. Figure 10 (c) displays the lineout taken along the energy coordinate of the Mn x-ray source $(x=0.85$ $\mathrm{mm}$ ), which is consistent with an unperturbed laser-generated He- $\alpha$ spectrum. Because of the high spectral resolution of the XRS3 diagnostic, the full complexity of the He- $\alpha$ Xray source was revealed, which had not been measured in previous XRTS studies [29, 30]. A close examination of the XRS3 image (Fig. 10 (a)) shows that the scattering spectrum is similar, but not identical to the source spectrum. At low energies $(6000-6100 \mathrm{eV})$, the intensities of the scattered signals of Z2661 are slightly raised, which may indicate some bound-free scattering from L-shell electrons in the $\mathrm{CH}_{2}$. Figure 10 (d) displays the $\mathrm{x}$-ray scattering spectra from the ambient $\mathrm{CH}_{2}(x=-0.20 \mathrm{~mm})$ and shocked $\mathrm{CH}_{2}(x=-0.60$ $\mathrm{mm}$ ) states. The experimental scattering spectra were consistent with the prediction that shocked and ambient spectra of the $\mathrm{CH}_{2}$ foam should be very similar due to the Z-XRTS experiment's modest temperature increase $(4.3 \mathrm{eV})$. For the predicted plasma conditions, the relative strength of the elastic peak is sensitive only to the concentration of scattering centers, which depends on the material density [36]. Thus, the intensity jump of the elastic signal is related to the density jump across the shock front. It is noted that 
although about a four times density jump was predicted, the corresponding XRTS signal does not increase by a similar factor across the jump. A detailed 3D scattering analysis to model the Z-XRTS data using the new SPECT3D scattering tool [56] is presented in another paper [57]. Briefly, in order to understand the structure of the scattered signal along the spatial direction, the analysis would involve forward calculations of the experiment that would account for various physical effects, such as the range of x-ray input angles, the attenuation of x-rays due to sample density and penetration depth, the sample's motion blur and lateral variations, and the spatial resolution of the instrument.

Distinguishing the $\mathrm{x}$-ray scattering signals between the shocked and ambient $\mathrm{CH}_{2}$ states was noticeably improved using Agfa D8 x-ray film on Z2704, as shown in its raw XRS3 image (see Figure 9 (b)) and corresponding filtered XRS3 image (see Figure 11 (a)). A lineout taken along the position coordinate at the Mn He- $\alpha$ resonance line $(E=$ $6181 \mathrm{eV}$ ) is shown in Figure 11 (b). The better spatial resolution of film enabled the two scattering peaks within the $\mathrm{CH}_{2}$ sample (at $x=-0.20,-0.60 \mathrm{~mm}$ ) to be more clearly observed on Z2704, which had been smeared together on the IP image of Z2661. Figure 11 (c) displays the lineout taken along the energy coordinate of the Mn x-ray source ( $x=$ $0.80 \mathrm{~mm}$ ), which revealed finer features due to the better spectral resolution of the x-ray film. Also, the Mn x-ray source spectrum of Z2704 was shown to be noticeably different from the source spectrum of Z2661, which demonstrates the importance of in situ source characterization. Figure 11 (d) displays the x-ray scattering spectra from the ambient $\mathrm{CH}_{2}(x=-0.20 \mathrm{~mm})$ and shocked $\mathrm{CH}_{2}(x=-0.60 \mathrm{~mm})$ states, and both spectra also showed the finer spectral features. However, the benefits of the Agfa D8 x-ray film's 
higher spatial and spectral resolutions should be weighed against its lowered x-ray sensitivity.

Because the forward scattering geometry involved a more stringent collimation of the x-ray source that reduced the x-ray fluence, the higher sensitivity IP was used in the XRS3 diagnostic on Z2750, which as shown in its raw and filtered XRS3 images (see Figure 9 (c) and Figure 12 (a), respectively) proved to be appropriate. A lineout taken along the position coordinate at the $\mathrm{Mn} \mathrm{He}-\alpha$ resonance line $(E=6181 \mathrm{eV})$ is shown in Figure 12 (b). The spatial dependence of the x-ray scattering of Z2750 was similar to that measured on Z2661, but showed better distinction between the ambient and shocked $\mathrm{CH}_{2}$ states. This was most likely due to the restricted x-ray scattering angles of $\mathrm{Z} 2750$ compared to the unconstrained x-ray scattering angles of Z2661. Figure 12 (c) displays the lineout taken along the energy coordinate of the Mn x-ray source $(x=0.75 \mathrm{~mm})$. Figure 12 (d) displays the $\mathrm{x}$-ray scattering spectra from the ambient $\mathrm{CH}_{2}(x=-0.20 \mathrm{~mm})$ and shocked $\mathrm{CH}_{2}(x=-0.70 \mathrm{~mm})$ states. The overall quality of the space-resolved $\mathrm{x}$-ray spectra measured by the XRS3 diagnostic demonstrated that the forward scattering geometry could be used on future Z-XRTS experiments.

A comparison of the three Z-XRTS experiments' spatial resolutions is presented by superimposing their spatial lineouts, normalized to their corresponding peak scattering intensities, on a single detailed plot, as shown in Figure 13. It is clear that best spatial resolution was achieved with the x-ray film on Z2704, despite having a broad range of scattering angle due the absence of an input aperture. For Z2704, measuring from the peak scattering intensity $(x=-0.58 \mathrm{~mm})$ to the minimum scattering intensity $(x=-0.45$ $\mathrm{mm}$ ) within the sample, the shock jump was spatially resolved to about $130 \mu \mathrm{m}$. The 
spatial resolution of Z2661, which used a combination of image plate and no input aperture, was sufficient to detect the shocked state based on the peak scattering intensity $(x=-0.56 \mathrm{~mm})$ within the sample, but it was an inadequate to definitely resolve a minimum scattering intensity. In comparison, while image plate was also fielded in Z2750, its spatial resolution was improved by the use of an input aperture to limit the range of scattering angles. In this case, measuring from the peak scattering intensity $(x=$ $-0.67 \mathrm{~mm})$ to the minimum scattering intensity $(x=-0.25 \mathrm{~mm})$ within the sample, the shock jump was spatially resolved to about $420 \mu \mathrm{m}$.

Because of the low SNR of the presented Z-XRTS experiments, the elastic scattering signals were clearly observed, but the weaker inelastic scattering signals proved to be more elusive. Although the scattering signals were adequate to demonstrate some density change across the shock front (whose detailed analysis will be presented another paper [57]), the temperature of the shock compressed WDM state could not be determined. It is noted that this was also partly due to the goal of these Z-XRTS experiment to first demonstrate that a space-resolved scattering signal from a WDM state could be measured on Z. For instance, the coaxial Z-DMP load design limited the Al flyer impact velocity to about $25 \mathrm{~km} / \mathrm{s}$, thus the resulting shocked $\mathrm{CH}_{2}$ foam WDM state only had a modest temperature increase. In combination with the $\mathrm{CH}_{2}$ foam's low free electron density, any inelastic scattering signal was expected to be quite small. In the next Z-XRTS experiment, a stripline Z-DMP load design [53] will be used to launch the Al flyer to about $33 \mathrm{~km} / \mathrm{s}$ to strongly shock compress a beryllium sample ( $10 \mathrm{Mbar}, \sim 5$ $\left.\mathrm{g} / \mathrm{cm}^{3}, \sim 4 \mathrm{eV}\right)$ that would have an expected free electron density $\left(\sim 7 \times 10^{23} \mathrm{~cm}^{-3}\right)$ large enough to produce detectable inelastic scattering signals. 
Finally, another goal of the next Z-XRTS experiment will be to improve the SNR, which will enable conclusive detection of inelastic scattering signals. First, there will be continuing work to increase the intensity of the Mn x-ray source, which includes improved ZBL alignment, focal spot quality and x-ray yield. Specifically, a more precise alignment/focus control will be installed on the ZBL final optical assembly, and an adaptive optics system will be implemented to compensate aberrations within the whole laser chain all the way to the target. Also, the x-ray background may be reduced though additional x-ray shielding of the XRS3 diagnostic. 


\section{Summary}

The goal of this work was to enable the advancement of WDM physics by combining the powerful XRTS diagnostic with the extreme environments created at the Sandia Z pulsed-power accelerator. The foundation for the new XRTS capability on the $\mathrm{Z}$ accelerator has been established through multiple dynamic compression experiments on carbon $\left(\mathrm{CH}_{2}\right)$ foam samples. The uniformly shocked $\mathrm{CH}_{2}$ foam's volume and steady state duration were about 1000 times larger and lasts 100 times longer, respectively, than typical laser shocked samples. The Z-Beamlet laser irradiated a Mn foil near the sample to generate $6.2 \mathrm{keV}$ x-rays that penetrated into the $\mathrm{CH}_{2}$ foam and scattered from it. A high sensitivity x-ray scattering spherical spectrometer with both high spectral $(4.8 \mathrm{eV})$ and spatial $(190 \mu \mathrm{m})$ resolution was fielded. For the first time, space-resolved scattered X-ray spectra from the sample regions ahead and behind the shock were recorded while the source x-ray spectrum was simultaneously measured on the same detector. Experimental efforts have achieved low x-ray background and mitigation of load debris, which have enabled the measurement of good quality XRTS data to validate the technique. Both backward and forward x-ray scattering geometries were investigated, and a comparison between the spectral and spatial resolutions, and sensitivities of image plate and x-ray film for recording XRTS data was performed. 


\section{Acknowledgements}

The authors would like to acknowledge the large team at Sandia that contributed to the design, fabrication, and fielding of the complex $\mathrm{Z}$ experiments. Sandia is a multiprogram laboratory operated by Sandia Corporation, a Lockheed Martin Company, for the U.S. Department of Energy's National Nuclear Securities Administration under Contract No. DE-AC04-94AL85000. Funding for part of this work was through the LDRD program at Sandia (Project 141540). 


\section{References}

1. S. Ichimaru, Rev. Mod. Phys. 54, 1017 (1982).

2. D. Saumon, G. Chabrier, and H. M. Van Horn, Astrophys. J. Suppl. Ser. 99, 713 (1995).

3. T. Guillot, Science 286, 72 (1999).

4. M. K. Matzen, M. A. Sweeney, R. G. Adams, J. R. Asay, J. E. Bailey, G. R. Bennett, D. E. Bliss, D. D. Bloomquist, T. A. Brunner, R. B. Campbell, G. A. Chandler, C. A. Coverdale, M. E. Cuneo, J.-P. Davis, C. Deeney, M. P. Desjarlais, G. L. Donovan, C. J. Garasi, T. A. Haill, C. A. Hall, D. L. Hanson, M. J. Hurst, B. Jones, M. D. Knudson, R. J. Leeper, R. W. Lemke, M. G. Mazarakis, D. H. McDaniel, T. A. Mehlhorn, T. J. Nash, C. L. Olson, J. L. Porter, P. K. Rambo, S. E. Rosenthal, G. A. Rochau, L. E. Ruggles, C. L. Ruiz, T. W. L. Sanford, J. F. Seamen, D. B. Sinars, S. A. Slutz, I. C. Smith, K. W. Struve, W. A. Stygar, R. A. Vesey, E. A. Weinbrecht, D. F. Wenger, and E. P. Yu, Phys. Plasmas 12, 055503 (2005).

5. J. D. Lindl, P. Amendt, R. L, Berger, S. G. Glendinning, S. H. Glenzer, S. W. Haan, R. L. Kauffman, O. L. Landen, and L. J. Sutter, Phys. Plasmas 11, 339 (2004).

6. B. Remington, R. P. Drake, and D. D. Ryutov, Rev. Mod. Phys. 78, 755 (2006).

7. R. B. Spielman, W. A. Stygar, J. F. Seaman, F. Long, H. Ives, R. Garcia, and T. Wagoner, Proceedings of the 11th IEEE International Pulsed Power Conference, Baltimore, MD, 29 June-2 July 1997, edited by G. Cooperstein and I. Vitkovitsky, (IEEE, Piscataway, NJ, 1997), Vol. 1, p. 709.

8. E. I. Moses and C. R. Wuest, Fusion Sci. Technol. 47, 314 (2005). 
9. T. R. Boehly, D. L. Brown, R. S. Craxton, R. L. Keck, J. P. Knauer, J. H. Kelly, T. J. Kessler, S. A. Kumpan, S. J. Loucks, S. A. Letzring, F. J. Marshall, R. L. McCrory, S. F. B. Morse, W. Seka, J. M. Soures, and C. P. Verdon. Opt. Commun. 133, 495 (1997).

10. R. W. Lee, S. J. Moon, H.-K. Chung, W. Rozmus, H. A. Baldis, G. Gregori, R. C. Cauble, O. L. Landen, J. S. Wark, A. Ng, S. J. Rose, C. L. Lewis, D. Riley, J.-C. Gauthier, and P. Audebert, J. Opt. Soc. Am. B 20, 770 (2003).

11. J. D. Molitoris, M. M. Morin, D. W. Phillion, A. L. Osterheld, R. E. Stewart, and S. D. Rothman, Rev. Sci. Instrum. 63, 5104 (1992).

12. B. A. Hammel, D. Griswold, O. L. Landen, T. S. Perry, B. A. Remington, P. L. Miller, T. A. Peyser, and J. D. Kilkenny, Phys. Fluids B 5, 2259 (1993).

13. D. B. Sinars, G. R. Bennett, D. F. Wenger, M. E. Cuneo, D. L. Hanson, J. L. Porter, R. G. Adams, P. K. Rambo, D. C. Rovang, and I. C. Smith, Rev. Sci. Instrum. 75, 3672 (2004).

14. D. Riley, N. C. Woolsey, D. McSherry, I. Weaver, A. Djaoui, and E. Nardi, Phys. Rev. Lett. 84, 1704 (2000).

15. D. H. Kalantar, J. F. Belak, G.W. Collins, J. D. Colvin, H. M. Davies, J. H. Eggert, T. C. Germann, J. Hawreliak, B. L. Holian, K. Kadau, P. S. Lomdahl, H. E. Lorenzana, M. A. Meyers, K. Rosolankova, M. S. Schneider, J. Sheppard, J. S. Stolken, and J. S. Wark, Phys. Rev. Lett. 95, 075502 (2005).

16. B. Yaakobi, F. J. Marshall, T. R. Boehly, R. P. J. Town, and D. D. Meyerhofer, J. Opt. Soc. Am. B 20, 238 (2003). 
17. P. Audebert, P. Renaudin, S. Bastiani-Ceccotti, J.-P. Geindre, C. Chenais-Popovics, S. Tzortzakis, V. Nagels-Silvert, R. Shepherd, I. Matsushima, S. Gary, F. Girard, O. Peyrusse, and J.-C. Gauthier, Phys. Rev. Lett. 94, 025004 (2005).

18. E. Seres, J. Seres, and C. Spielmann, Appl. Phys. Lett. 89, 181919 (2006).

19. A. Levy, F. Dorchies, M. Harmand, C. Fourment, S. Hulin, O. Peyrusse, J. J. Santos, P. Antici, P. Audebert, J. Fuchs, L. Lancia, A. Mancic, M. Nakatsutsumi, S. Mazevet, V. Recoules, P. Renaudin, and S. Fourmaux, Plasma Phys. Control. Fusion 51, 124021 (2009).

20. S. H. Glenzer and R. Redmer, Rev. Mod. Phys. 81, 1625 (2009).

21. O. L. Landen, S. H. Glenzer, M. J. Edwards, R. W. Lee, G. W. Collins, R. C. Cauble, W. W. Hsing, and B. A. Hammel, J. Quant. Spectrosc. Radiat. Transf. 71, 465 (2001).

22. S. H. Glenzer, G. Gregori, R. W. Lee, F. J. Rogers, S. W. Pollaine, and O. L. Landen, Phys. Rev. Lett. 90, 175002 (2003).

23. S. H. Glenzer, O. L. Landen, P. Neumayer, R. W. Lee, K. Widmann, S. W. Pollaine, and R. J. Wallace, Phys. Rev. Lett. 98, 065002 (2007).

24. H. Sawada, S. P. Regan, D. D. Meyerhofer, E. V. Igumenshchev, V. N. Goncharov, T. R. Boehly, R. Epstein, T. C. Sangster, V. A. Smalyuk, B. Yaakobi, G. Gregori, S. H. Glenzer, and O. L. Landen, Phys. Plasmas 14, 122703 (2007).

25. A. Ravasio, G. Gregori, A. Benuzzi-Mounaix, J. Daligault, A. Delserieys, A. Y. Faenov, B. Loupias, N. Ozaki, M. R. le Gloahec, T. A. Pikuz, D. Riley, and M. Koenig, 2007, Phys. Rev. Lett. 99, 135006 (2007).

26. D. Riley, F. Y. Khattak, E. G. Saiz, G. Gregori, S. Bandyopadhyay, M. Notley, D. Neely, D. Chambers, A. Moore, and A. Comley, Laser Part. Beams 25, 465 (2007). 
27. E. G. Saiz, G. Gregori, D. O. Gericke, J. Vorberger, B. Barbrel, R. J. Clarke, R. R. Freeman, S. H. Glenzer, F. Y. Khattak, M. Koenig, O. L. Landen, D. Neely, P. Neumayer, M. M. Notley, A. Pelka, D. Price, M. Roth, M. Schollmeier, C. Spindloe, R. L. Weber, L. van Woerkom, K. Wunsch, and D. Riley, Nature Phys. 4, 940 (2008).

28. A. L. Kritcher, P. Neumayer, J. Castor, T. Döppner, R. W. Falcone, O. L. Landen, H. J. Lee, R. W. Lee, B. Holst, R. Redmer, E. C. Morse. A. Ng, S. W. Pollaine, D. Price, and S. H. Glenzer, Science 322, 69 (2008).

29. H. J. Lee, P. Neumayer, J. Castor, T. Döppner, R. W. Falcone, C. Fortmann, B. A. Hammel, A. L. Kritcher, O. L. Landen, R. W. Lee, D. D. Meyerhofer, D. H. Munro, R. Redmer, S. P. Regan, S. Weber, and S. H. Glenzer, Phys. Rev. Lett. 102, 115001 (2009).

30. C. Fortmann C, H. J. Lee, T. Döppner, R. W. Falcone, A. L. Kritcher, O. L. Landen, and S. H. Glenzer, Phys. Rev. Lett. 108, 175006 (2012).

31. S. Le Pape, P. Neumayer, C. Fortmann, T. Döppner, P. Davis, A. Kritcher, O. Landen, and S. Glenzer, Phys. Plasmas 17, 056309 (2010).

32. A. K. Freund, A. Munkholm, and S. Brennan, Proc. SPIE 2856, 68 (1996).

33. A. Shevelko, A. Antonov, I. Grigorieva, Y. Kasyanov, O. Yakushev, L. Knight, and Q. Wang, Proc. SPIE 4144, 148 (2000).

34. A. P. Shevelko, Y. S. Kasyanov, O. F. Yakushev, L. V. Knight, Rev. Sci. Instrum. 73, 3458 (2002).

35. E. J. Gamboa, C. M. Huntington, M. R. Trantham, P. A. Keiter, R. P. Drake, D. S. Montgomery, J. F. Benage, and S. A. Letzring, Rev. Sci. Instrum. 83, 10E108 (2012). 
36. E. J. Gamboa, R. P. Drake, K. Falk, P. A. Keiter, D. S. Montgomery, J. F. Benage, and M. R. Trantham, Phys. Plasmas 21, 042701 (2014).

37. M. D. Knudson, R. W. Lemke, D. B. Hayes, C. A. Hall, C. Deeney, and J. R. Asay, J. Appl. Phys. 94, 4420 (2003).

38. R. W. Lemke, M. D. Knudson, D. E. Bliss, K. Cochrane, J.-P. Davis, A. A. Giunta, H. C. Harjes, and S. A. Slutz, J. Appl. Phys. 98, 073530 (2005).

39. A. C. Robinson, T. A. Brunner, S. Carroll, R. Drake, C. J. Garasi, T. Gardiner, T. Haill, H. Hanshaw, D. Hensinger, D. Labreche, R. Lemke, E. Love, C. Luchini, S. Mosso, J. Niederhaus, C. C. Ober, S. Petney, W. J. Rider, G. Scovazzi, O. E. Strack, R. Summers, T. Trucano, V. G. Weirs, M. Wong, and T. Voth, AIAA-2008-1235, Proceedings of the 46th AIAA Aerospace Sciences Meeting, Reno, NV, January 2008.

40. P. K. Rambo, I. C. Smith, J. L. Porter, Jr., M. J. Hurst, C. S. Speas, R. G. Adams, A. J. Garcia, E. Dawson, B. D. Thurstron, C. Wakefield, J. W. Kellogg, M. J. Slattery, H. C. Ives III, R. S. Broyles, J. A. Caird, A. C. Erlandson, J. E. Murray, W. C. Behrendt, N. D. Neilsen, and J. M. Narduzzi, Appl. Opt. 44, 2421 (2005).

41. J. Workman and G. A. Kyrala, Proc. SPIE Vol. 4504, 168 (2001).

42. D. B. Sinars, G. A. Chandler, J. E. Bailey, R. C. Mancini, G. A. Rochau, D. F. Wenger, R. G. Adams, M. L. Adams, H. A. Scott, A. Ya. Faenov, T. A. Pikuz, S. A. Pikuz, J. Quant. Spectrosc. Radiat. Transf. 99, 595 (2006).

43. S. G. Gales and C. D. Bentley, Rev. Sci. Instrum. 75, 4001 (2004).

44. Y. Amemiya and J. Miyahara, Nature 336, 89 (1988).

45. N. E. Lanier, J. S. Cowan, and J. Workman, Rev. Sci. Instrum. 77, 043504 (2006).

46. N. E. Lanier and J. S. Cowan, Rev. Sci. Instrum. 85, 11D632 (2014). 
47. E. C. Harding, T. Ao, J. E. Bailey, G. Loisel, D. B. Sinars, M. Geissel, G. A. Rochau, and I. C. Smith, Rev. Sci. Instrum. 86, 043504 (2015).

48. T. Ao, E. C. Harding, J. E. Bailey, G. Loisel, S. Patel, D. B. Sinars, L. P. Mix, and D. F. Wenger, J. Quant. Spectrosc. Radiat. Transf. 144, 92 (2014).

49. L. Barker and R. Hollenbach, J. Appl. Phys. 43, 4669 (1972).

50. W. F. Hemsing, Rev. Sci. Instrum. 50, 73 (1979).

51. R. B. Spielman, C. Deeney, G. A. Chandler, M. R. Douglas, D. L. Fehl, M. K. Matzen, D. H. McDaniel, T. J. Nash, J. L. Porter, T. W. L. Sanford, J. F. Seamen, W. A. Stygar, K. W. Struve, S. P. Breeze, J. S. McGurn, J. A. Torres, D. M. Zagar, T. L. Gilliland, D. O. Jobe, J. L. McKenney, R. C. Mock, M. Vargas, T. Wagoner, and D. L. Peterson, Phys. Plasmas 5, 2105, (1998).

52. J. E. Bailey, G. A. Chandler, S. A. Slutz, G. R. Bennett, G. Cooper, J. S. Lash, S. Lazier, R. Lemke, T. J. Nash, D. S. Nielsen, T. C. Moore, C. L. Ruiz, D. G. Schroen, R. Smelser, J. Torres, and R. A. Vesey, Phys. Rev. Lett. 89, 095004 (2002).

53. R. W. Lemke, M. D. Knudson, and J-P Davis, Int. J. Impact Eng. 38, 480 (2011).

54. T. Ao, E. C. Harding, J. E. Bailey, M. P. Desjarlais, S B Hansen, R. W. Lemke, G. A. Rochau, D. B. Sinars, I. C. Smith, M. Geissel, J. Reneker, M. D. Kernaghan, L. P. Mix and D. F. Wenger, Journal of Physics: Conference Series 500, 082001 (2014).

55. G. Fiksel, F. J. Marshall, C. Mileham, and C. Stoeckl, Rev. Sci. Instrum. 83, 086103 (2012).

56. I. Golovkin, J. J. MacFarlane, P. Woodruff, I. Hall, G. Gregori, J. Bailey, E. Harding, T. Ao, and S. Glenzer, High Energy Density Phys. 9, 510 (2013). 
57. E. C. Harding, T. Ao, J. E. Bailey, et al., "SPECT3D analysis of x-ray Thomson scattering on the Z accelerator”, Phys. Plasmas, to be submitted (2015). 


\section{Tables}

Table 1. Measured Al flyer impact velocities and times; compared to the expected impact velocity of $U_{A L E G R A-i m p a c t}=25.24 \mathrm{~km} / \mathrm{s}$, and the expected impact time of $t_{\text {ALEGRA- }}$ impact $=3265 \mathrm{~ns}$.

\begin{tabular}{|c|c|c|}
\hline Shot \# & $\begin{array}{c}\text { Impact velocity } \\
\mathbf{( k m} / \mathbf{s})\end{array}$ & $\begin{array}{c}\text { Impact time } \\
\mathbf{( n s )}\end{array}$ \\
\hline $\mathrm{Z} 2661$ & $25.47 \pm 0.11$ & $3264.3 \pm 0.4$ \\
\hline $\mathrm{Z} 2704$ & $25.41 \pm 0.05$ & $3265.2 \pm 0.4$ \\
\hline $\mathrm{Z} 2750$ & $25.62 \pm 0.10$ & $3262.1 \pm 0.7$ \\
\hline
\end{tabular}

Table 2. Measured $\mathrm{CH}_{2}$ foam sample parameters, shock breakout times, and shock velocities.

\begin{tabular}{|c|c|c|c|c|c|c|}
\hline \multirow{3}{*}{ Shot \# } & \multicolumn{5}{|c|}{ Ambient $\mathbf{C H}_{2}$} & \multicolumn{2}{c|}{ Shocked $\mathbf{C H}_{2}$} \\
\cline { 2 - 7 } & Density & Width & Height & Thickness & Breakout Time & Velocity \\
& $\left(\mathbf{g} / \mathbf{c m}^{\mathbf{3}}\right)$ & $(\mathbf{m m})$ & $(\mathbf{m m})$ & $(\mathbf{m m})$ & $(\mathbf{n s})$ & $(\mathbf{k m} / \mathbf{s})$ \\
\hline Z2661 & $0.110 \pm 0.008$ & $5.283 \pm 0.023$ & $7.720 \pm 0.005$ & $2.501 \pm 0.016$ & $3350.4 \pm 1.3$ & $29.05 \pm 0.49$ \\
\hline Z2704 & $0.121 \pm 0.006$ & $5.272 \pm 0.057$ & $7.677 \pm 0.008$ & $2.492 \pm 0.018$ & $3352.5 \pm 1.2$ & $28.55 \pm 0.45$ \\
\hline Z2750 & $0.114 \pm 0.008$ & $5.116 \pm 0.033$ & $7.582 \pm 0.044$ & $2.510 \pm 0.012$ & $3347.4 \pm 0.6$ & $29.41 \pm 0.31$ \\
\hline
\end{tabular}

Table 3. Measured ZBL energies, pulse durations, pre-pulse lead times, and expected and measured arrival times.

\begin{tabular}{|c|c|c|c|c|c|c|c|c|}
\hline \multirow{2}{*}{ Shot \# } & \multirow{2}{*}{$\begin{array}{c}\text { Total } \\
\text { energy } \\
\text { (J) }\end{array}$} & \multicolumn{3}{|c|}{ Pre-pulse } & \multicolumn{2}{|c|}{ Main-pulse } & \multicolumn{2}{|c|}{$\begin{array}{c}\text { Arrival time } \\
\text { (ns) }\end{array}$} \\
\hline & & $\begin{array}{c}\text { Energy } \\
\text { (J) }\end{array}$ & $\begin{array}{c}\text { Duration } \\
\text { (ns) }\end{array}$ & $\begin{array}{c}\text { Lead time } \\
\text { (ns) }\end{array}$ & $\begin{array}{c}\text { Energy } \\
\text { (J) }\end{array}$ & $\begin{array}{c}\text { Duration } \\
\text { (ns) }\end{array}$ & Expected & Measured \\
\hline Z2661 & $2980 \pm 300$ & $400 \pm 40$ & $0.4 \pm 0.1$ & $3.3 \pm 0.2$ & $2580 \pm 260$ & $2.0 \pm 0.2$ & 3335 & $3335.0 \pm 1.0$ \\
\hline $\mathrm{Z} 2704$ & $3480 \pm 350$ & $230 \pm 25$ & $0.4 \pm 0.1$ & $1.8 \pm 0.2$ & $3250 \pm 330$ & $3.5 \pm 0.2$ & 3335 & $3333.6 \pm 1.0$ \\
\hline $\mathrm{Z} 2750$ & $3950 \pm 400$ & $150 \pm 15$ & $0.4 \pm 0.1$ & $1.9 \pm 0.2$ & $3800 \pm 380$ & $3.5 \pm 0.2$ & 3335 & $3334.8 \pm 1.0$ \\
\hline
\end{tabular}


Table 4. Measured XRS3 x-ray background, x-ray source, and x-ray scattering signals.

\begin{tabular}{|c|c|c|c|c|c|c|c|c|}
\hline \multirow{2}{*}{ Shot \# } & \multicolumn{2}{|c|}{ X-ray background } & \multicolumn{2}{c|}{ X-ray source } & \multicolumn{3}{c|}{ X-ray scattering } \\
\cline { 3 - 9 } & \multirow{2}{*}{ Baseline } & Noise & Signal & SNR & \multicolumn{2}{|c|}{ Ambient } & \multicolumn{2}{c|}{ Shocked } \\
\cline { 5 - 9 } & & & & & Signal & SNR & Signal & SNR \\
\hline Z2661 & 0.334 PSL & 0.045 PSL & 3.542 PSL & 71.2 & 0.550 PSL & 4.8 & 0.845 PSL & 11.3 \\
\hline Z2704 & 0.135 OD & 0.027 OD & 0.434 OD & 11.1 & 0.215 OD & 3.0 & 0.258 OD & 4.6 \\
\hline Z2750 & 0.099 PSL & 0.022 PSL & 0.354 PSL & 11.6 & 0.184 PSL & 3.9 & 0.257 PSL & 7.8 \\
\hline
\end{tabular}




\section{Figure captions}

Figure 1. Schematic (cross-section view) of Z-XRTS experiment showing the inside the $\mathrm{Z}$ target chamber with the Z-DMP load, XRS3 diagnostic, and ZBL.

Figure 2. (a) Illustration of the side view of Z-DMP coaxial load (one side, shorting cap not shown), and focusing of ZBL onto Mn foil, and (b) the expanded top view after impact of $\mathrm{Al}$ flyer onto $\mathrm{CH}_{2}$ foam, and propagation of shock in foam for x-ray scattering.

Figure 3. Schematic of Z-DMP coaxial load (cross-section view) showing the $\mathrm{CH}_{2}$ foam samples, various window samples (sapphire, quartz, lithium fluoride, calcium fluoride, and TPX), mounted VISAR probes, and ZBL irradiation of the Mn foil.

Figure 4. ALEGRA calculations of the (a) density, and (b) temperature profiles after impact of an Al flyer $(25 \mathrm{~km} / \mathrm{s})$ on an ambient $\mathrm{CH}_{2}$ foam $\left(0.12 \mathrm{~g} / \mathrm{cm}^{3}\right)$ to produce a 0.75 Mbar shocked $\mathrm{CH}_{2}$ foam.

Figure 5. Photographs of Z-DMP load hardware: (a) back view of north assembly load samples and diagnostic line-of-sights for the XRS3 and XPC diagnostics, and (b) detailed view of XRS3 field-of-view of XRTS $\mathrm{CH}_{2}$ foam sample.

Figure 6. (a) Illustration of the XPC's line-of-sight, and (b) the measured image of the $6.2 \mathrm{keV}$ x-rays generated from the Mn foil irradiated by ZBL (Z2661). 
Figure 7. (a) Illustration (top view) of the possible scattering angles for (a) backward scattering geometry (Z2661 and Z2704) with no limiting of incident x-rays, and (b) forward scattering geometry (Z2750) with an Au foil aperture to limit incident $\mathrm{x}$-rays.

Figure 8. VISAR measurements of Al flyer velocity profile compared to ALEGRA predicted velocity profile on (a) Z2661 (UVISAR-impact $=25.47 \mathrm{~km} / \mathrm{s})$, (b) Z2704 (UVISARimpact $=25.41 \mathrm{~km} / \mathrm{s})$, and $(\mathrm{c})$ Z2750 $\left(U_{\text {VISAR-impact }}=25.62 \mathrm{~km} / \mathrm{s}\right)$.

Figure 9. XRS3 measurements of the Mn x-ray source, and x-ray scattering from shocked and ambient $\mathrm{CH}_{2}$ foam on (a) Z2661, (b) Z2704, and (c) Z2750.

Figure 10. Z2661: Filtered XRS3 data of (a) spectrally and spatially resolved x-ray image; (b) position lineout along Mn He- $\alpha$ resonance line $(E=6181 \mathrm{eV})$ line; (c) energy lineout of Mn x-ray source $(x=0.85 \mathrm{~mm})$; (d) energy lineouts of x-ray scattering from ambient $\mathrm{CH}_{2}$ foam $(x=-0.20 \mathrm{~mm})$ and shocked $\mathrm{CH}_{2}$ foam $(x=-0.60 \mathrm{~mm})$.

Figure 11. Z2704: Filtered XRS3 data of (a) spectrally and spatially resolved x-ray image; (b) position lineout along Mn He- $\alpha$ resonance line $(E=6181 \mathrm{eV})$ line; (c) energy lineout of Mn x-ray source $(x=0.80 \mathrm{~mm})$; (d) energy lineouts of x-ray scattering from ambient $\mathrm{CH}_{2}$ foam $(x=-0.20 \mathrm{~mm})$ and shocked $\mathrm{CH}_{2}$ foam $(x=-0.60 \mathrm{~mm})$. 
Figure 12. Z2750: Filtered XRS3 data of (a) spectrally and spatially resolved x-ray image; (b) position lineout along Mn He- $\alpha$ resonance line $(E=6181 \mathrm{eV})$ line; (c) energy lineout of Mn x-ray source $(x=0.75 \mathrm{~mm})$; (d) energy lineouts of x-ray scattering from ambient $\mathrm{CH}_{2}$ foam $(x=-0.20 \mathrm{~mm})$ and shocked $\mathrm{CH}_{2}$ foam $(x=-0.70 \mathrm{~mm})$.

Figure 13. Position lineouts along Mn He- $\alpha$ resonance line $(E=6181 \mathrm{eV})$ line of Z2661, Z2704, and Z2750 that have been normalized to their corresponding peak scattering intensities. 


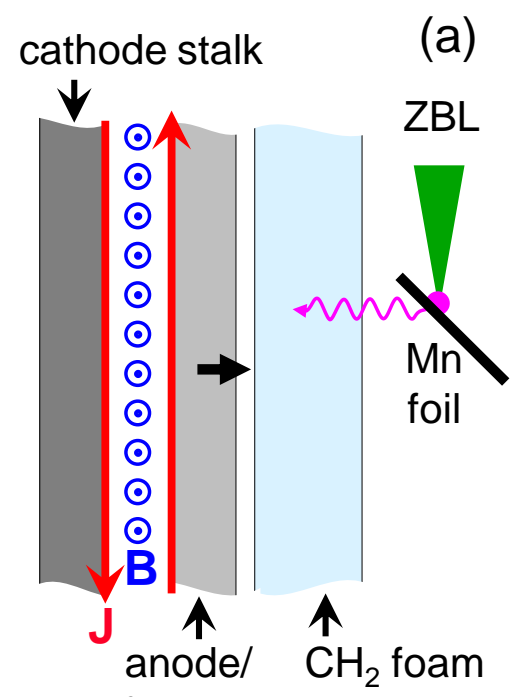

Al flyer plate

anode/

(b)

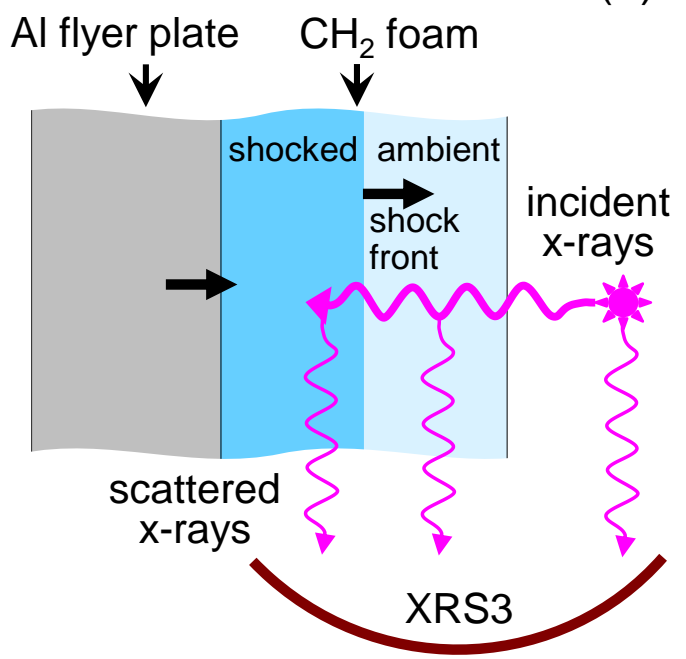




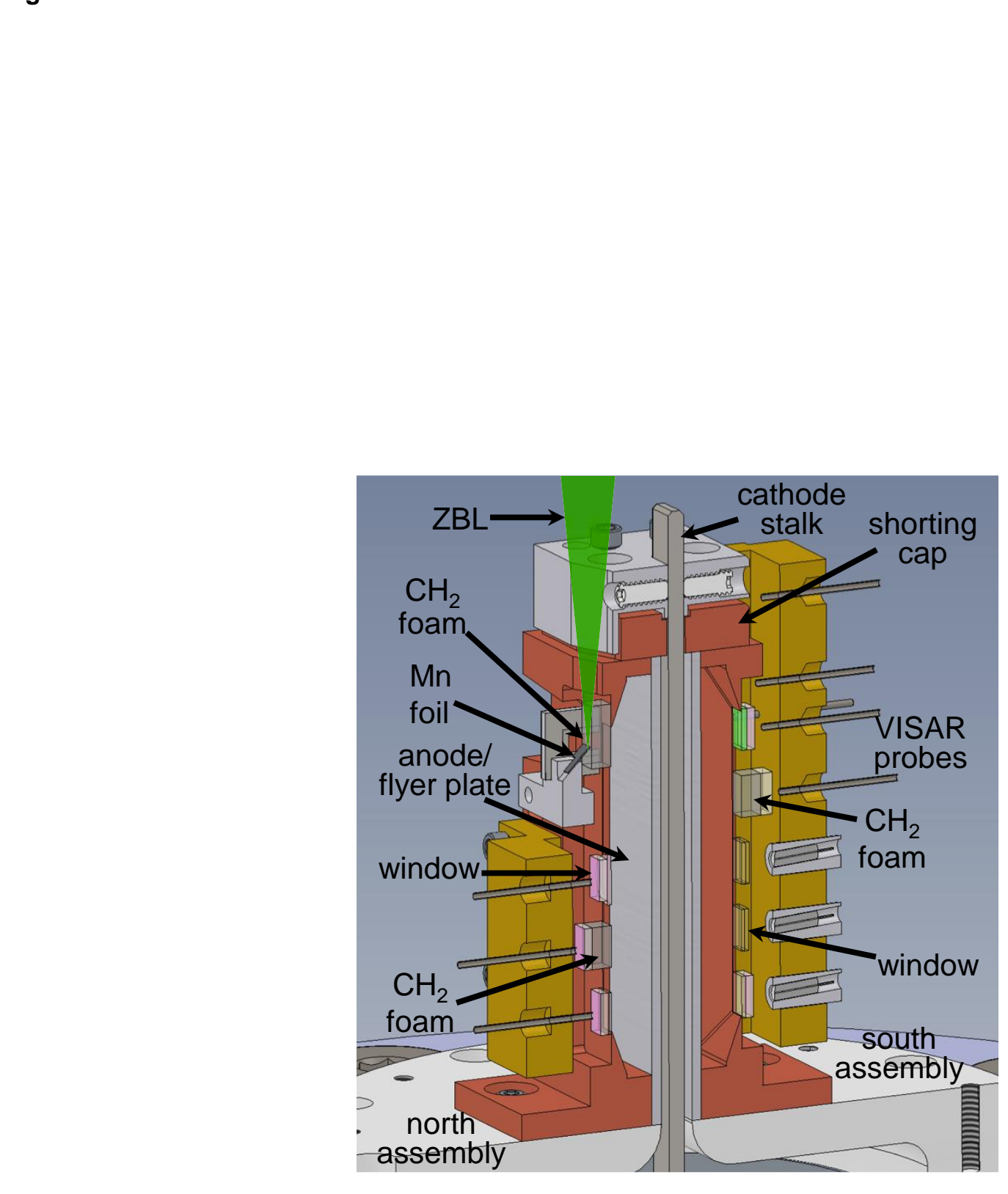

Figure 3

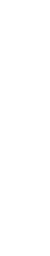

3
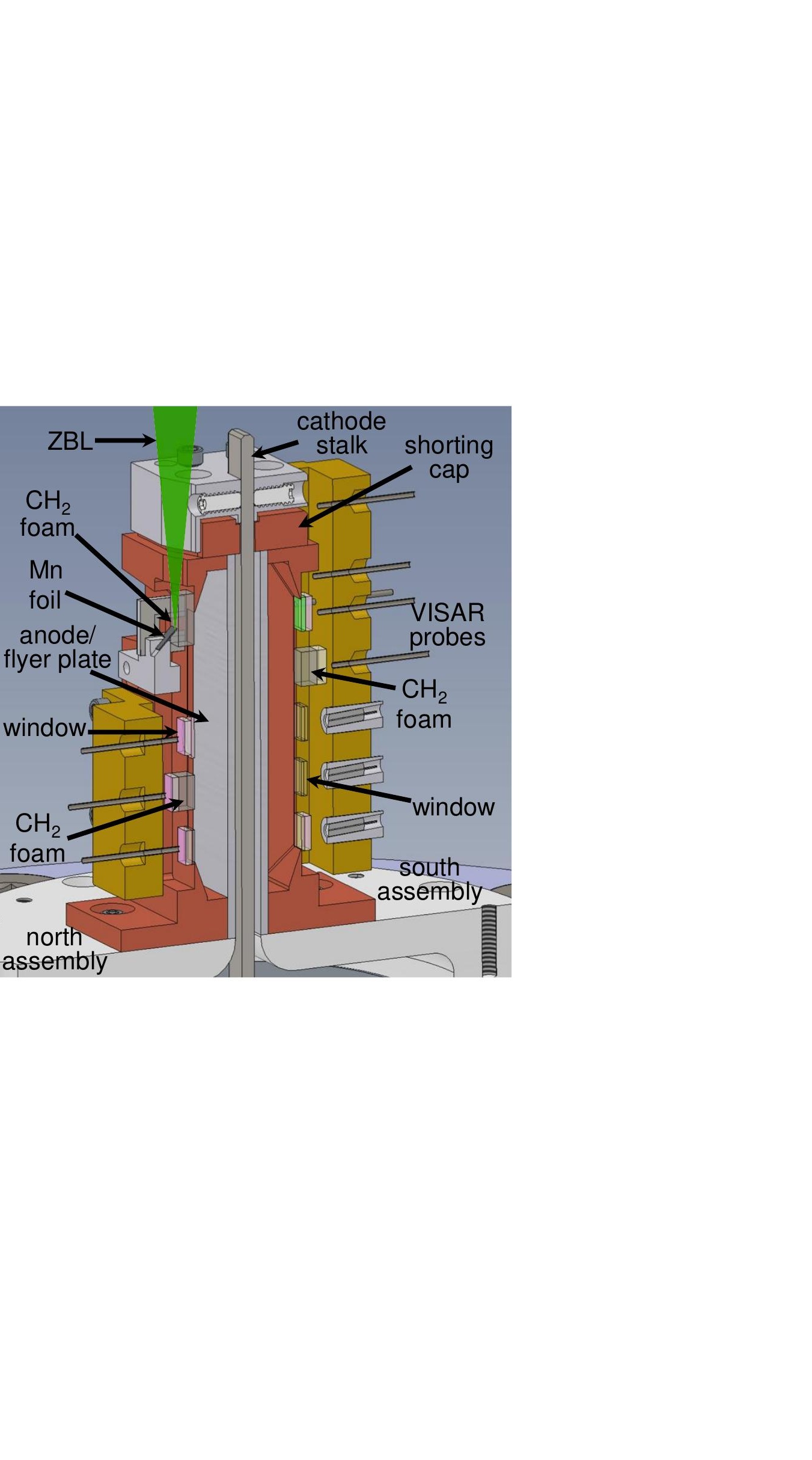

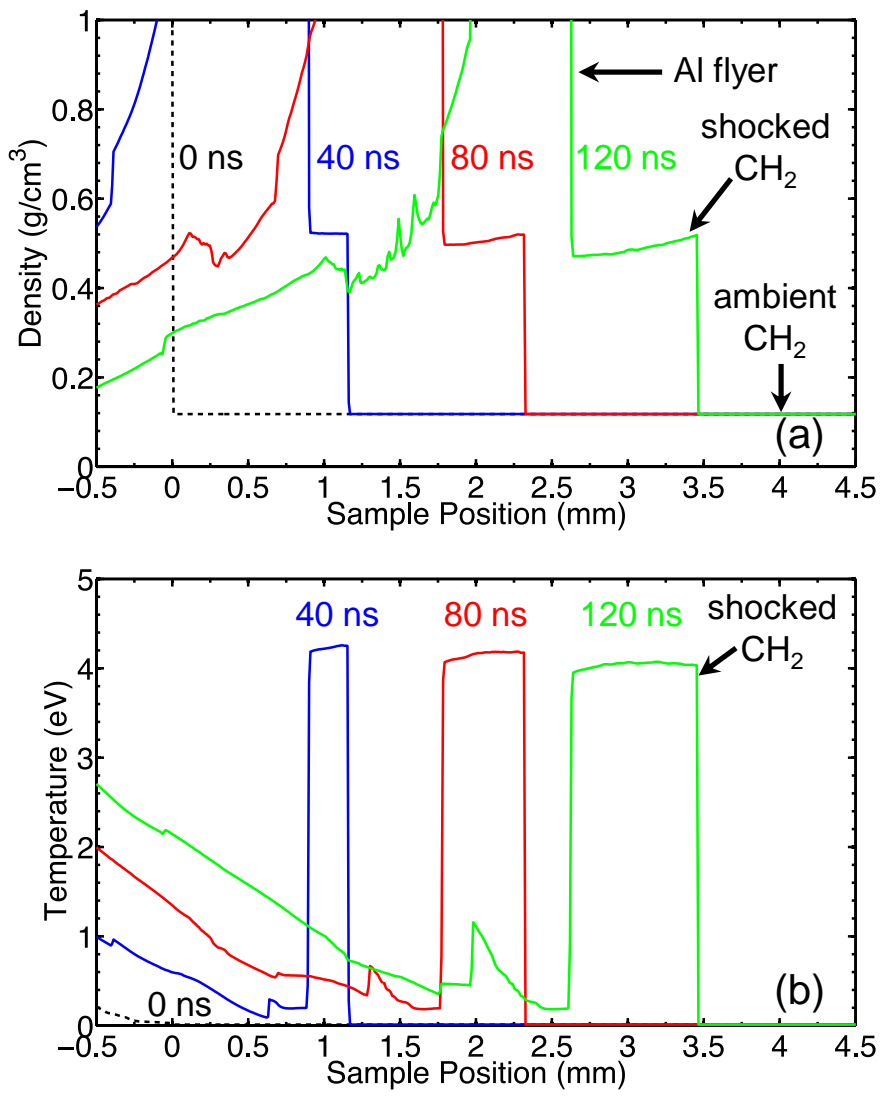


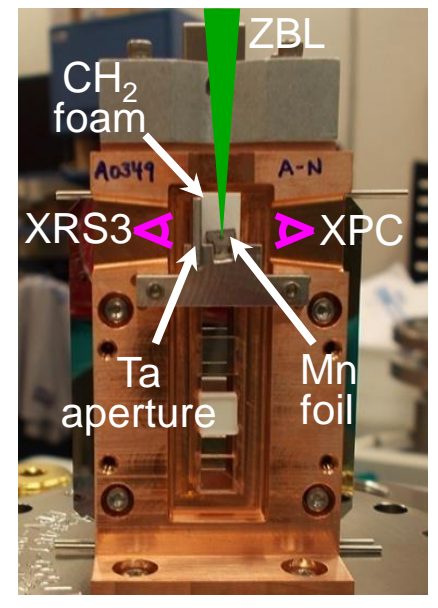

(a)

(a)

(

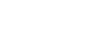

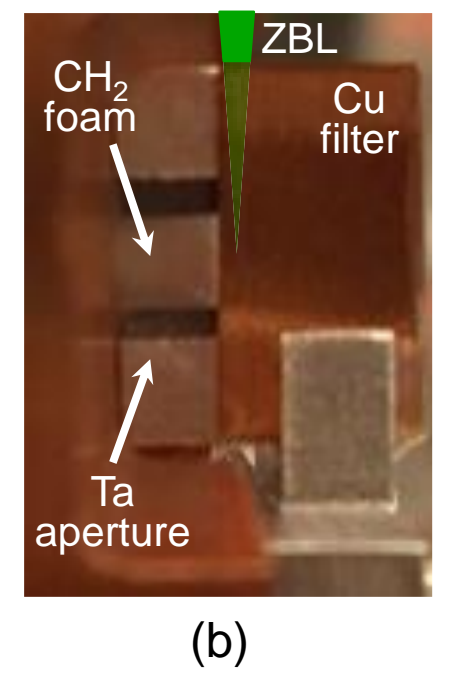

(b) filte (

Figure 5

Figure 5

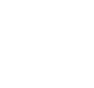
( 

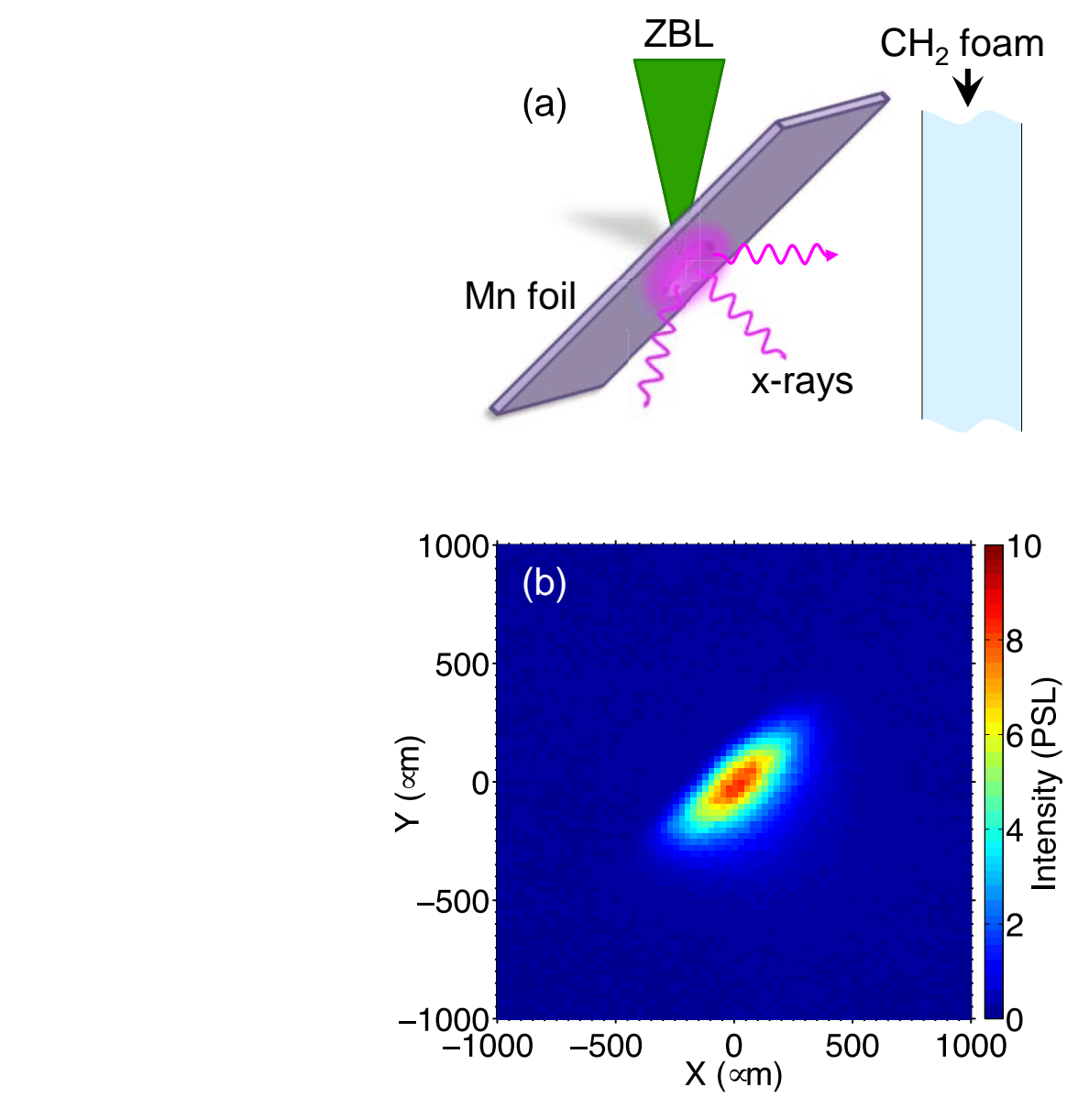

Figure 6

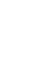

.

Figure 6 


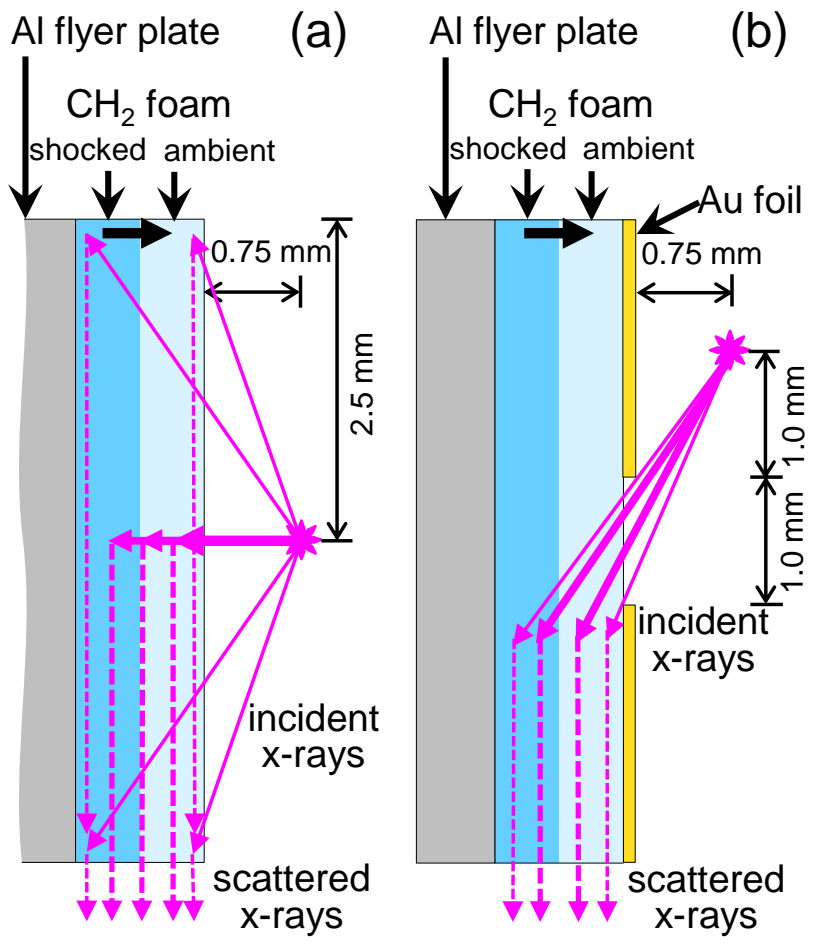



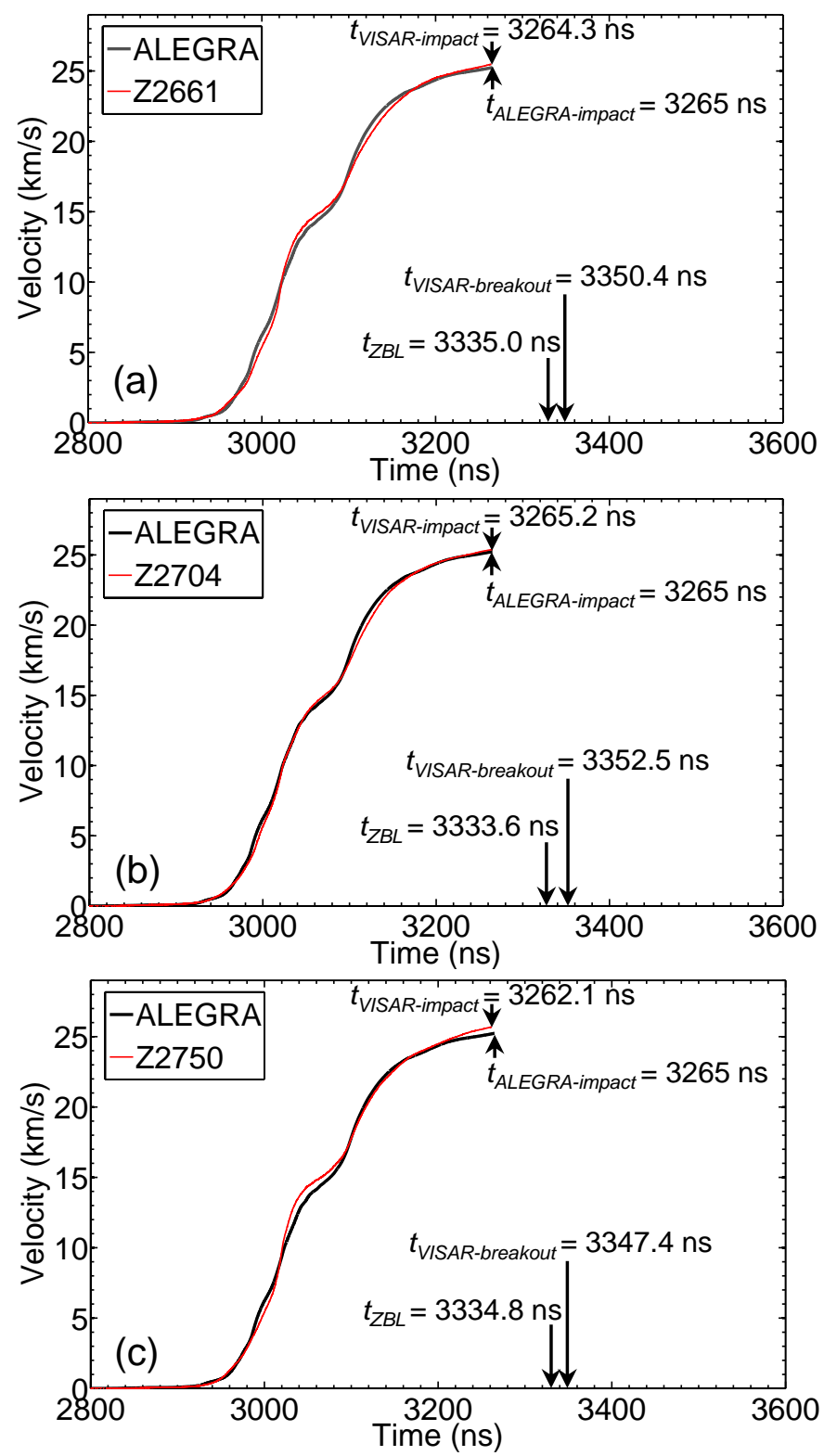

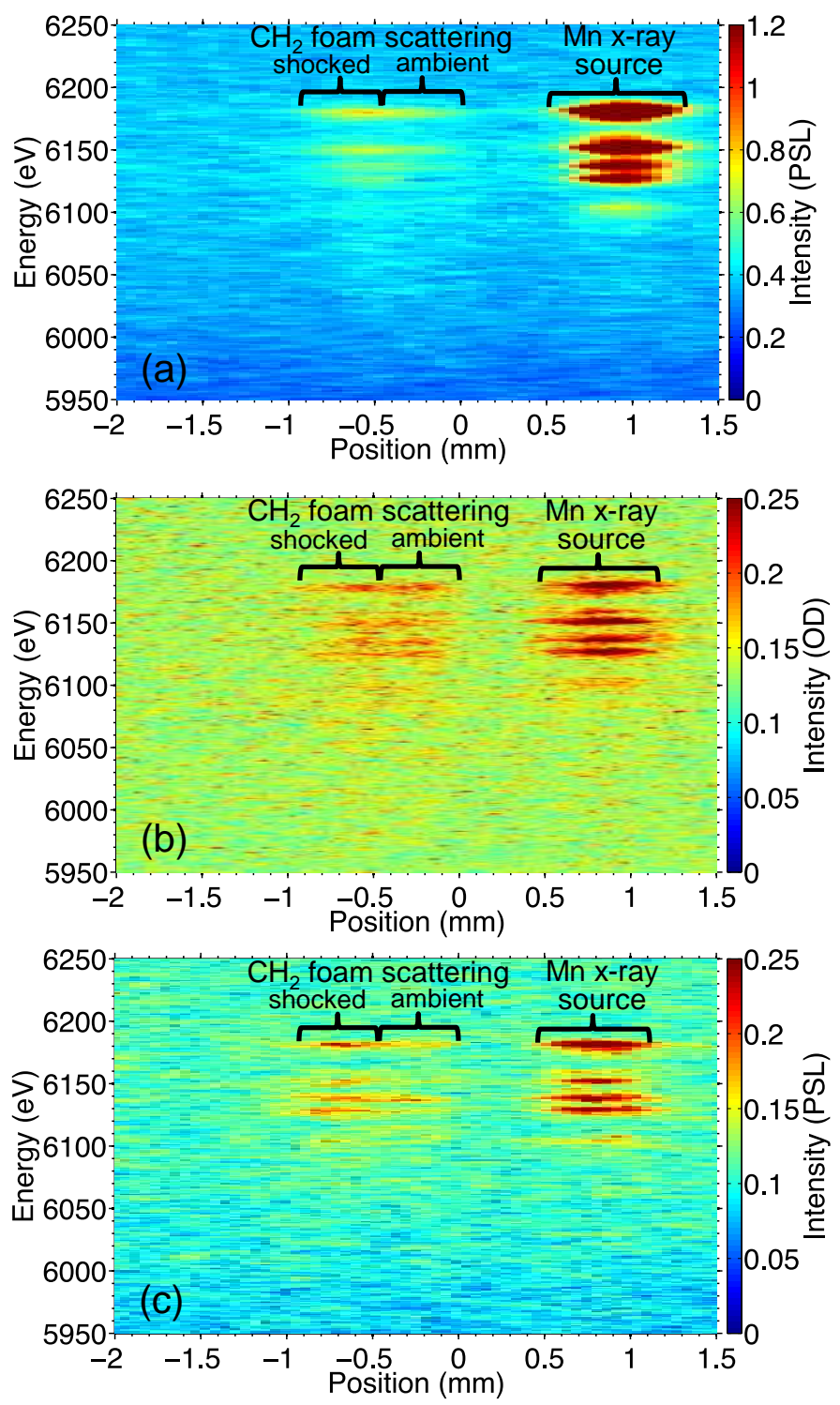

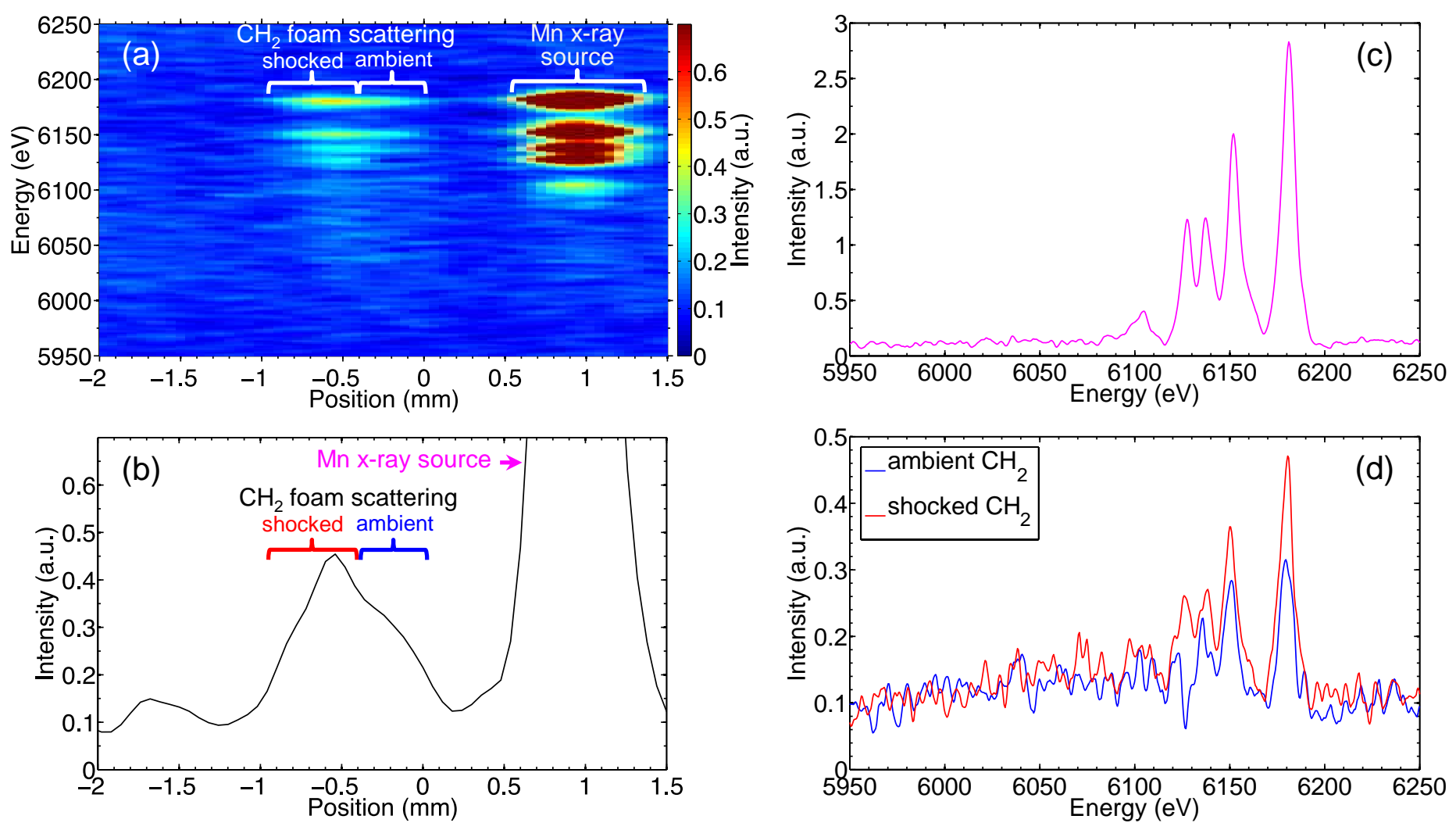

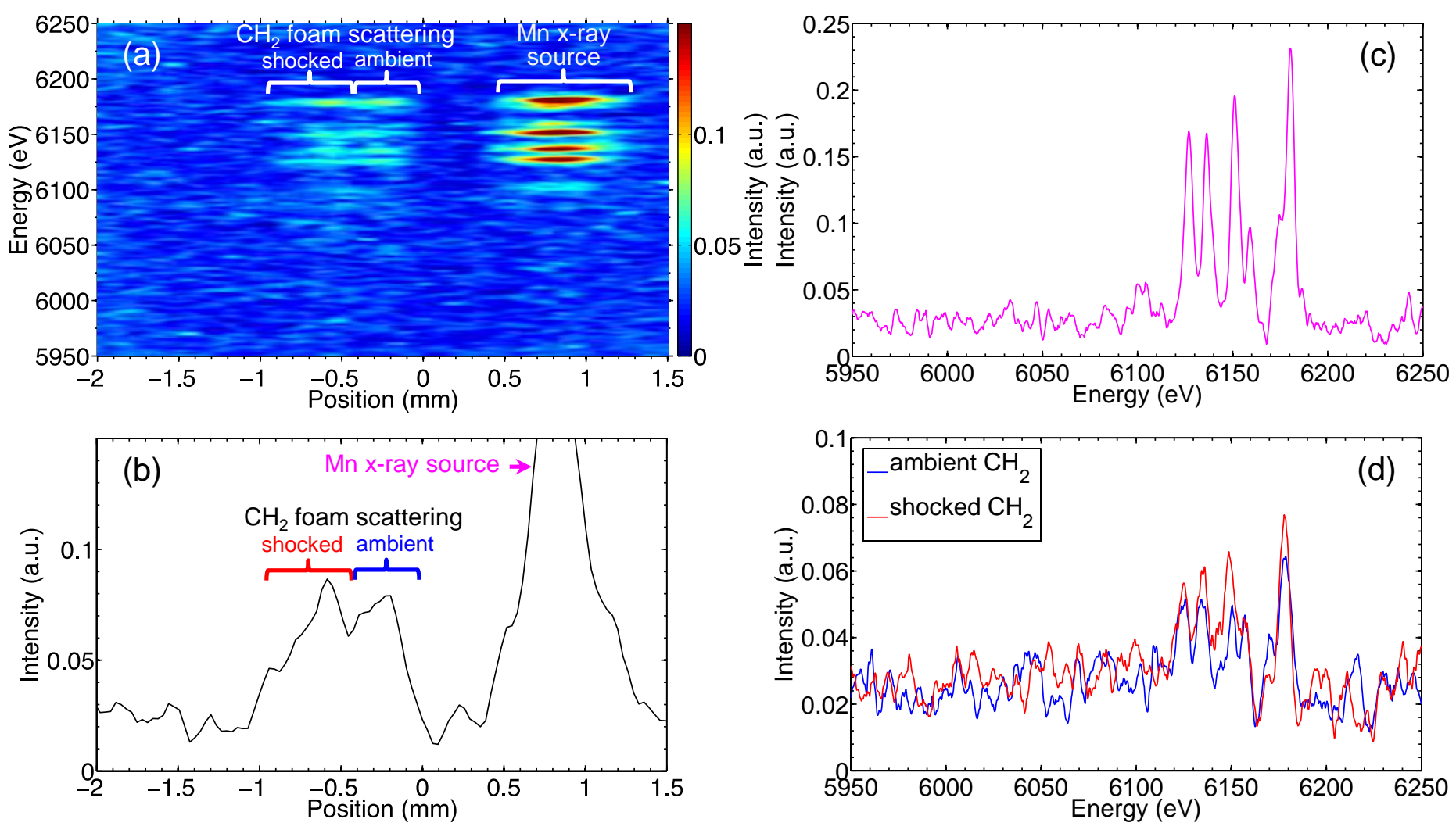

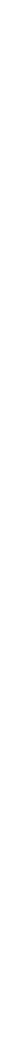
Figure 13

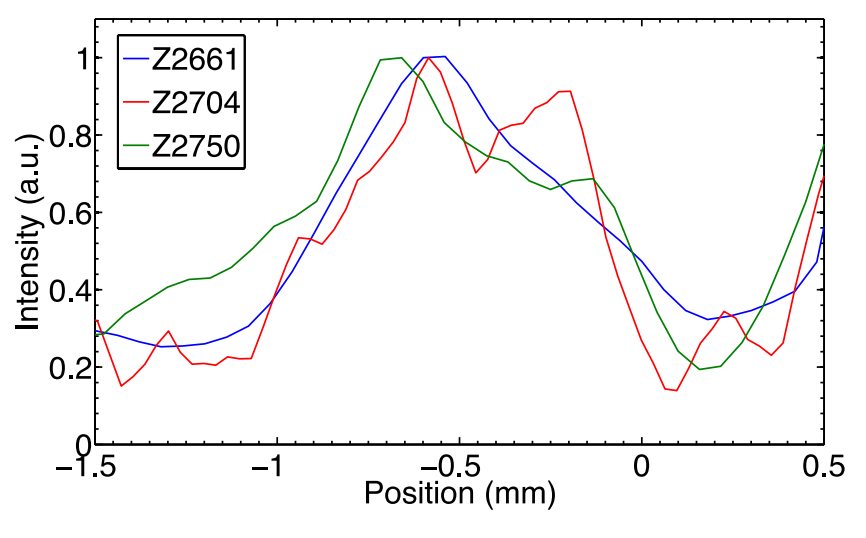

Position (mm)

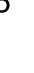

西

